GISELE DIAS DE FREITAS

Comparação entre o crescimento de Unidades Formadoras de Colônias (UFC) de Staphylococcus spp. e Klebsiella pneumoniae e a sensibilidade destas cepas ao processo de pasteurização lenta

São Paulo

2007 


\title{
Comparação entre o crescimento de Unidades Formadoras de Colônias (UFC) de Staphylococcus spp. e Klebsiella pneumoniae e a sensibilidade destas cepas ao processo de pasteurização lenta
}

\author{
Dissertação apresentada ao Programa de \\ Pós-Graduação em Epidemiologia \\ Experimental e Aplicada à Zoonoses da \\ Faculdade de Medicina Veterinária e \\ Zootecnia da Universidade de São Paulo para \\ obtenção do título de Mestre em Medicina \\ Veterinária \\ Departamento: \\ Medicina Veterinária Preventiva e \\ Saúde Animal \\ Área de concentração: \\ Epidemiologia Experimental e \\ Aplicada às Zoonoses \\ Orientador: \\ Prof. Dr. Nilson R. Benites
}


Autorizo a reprodução parcial ou total desta obra, para fins acadêmicos, desde que citada a fonte.

DADOS INTERNACIONAIS DE CATALOGAÇÃO-NA-PUBLICAÇÃO

(Biblioteca Virginie Buff D'Ápice da Faculdade de Medicina Veterinária e Zootecnia da Universidade de São Paulo)

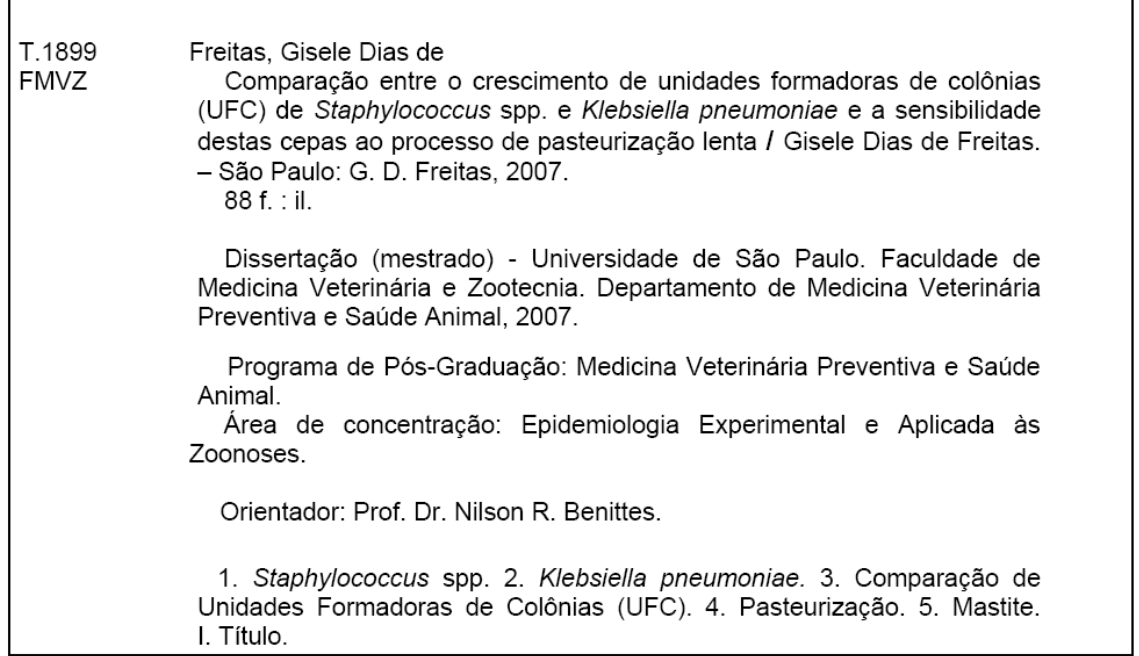




\section{UNIVERSIDADE DE SÃO PAULO Faculdade de Medicina Veterinaria e Zootecnia Assistência Acadêmica \\ Comissão de Bioética \\ CERTIFICADO}

Certificamos que o Projeto intitulado "Estudo de unidades formadoras de colônias, no leite, de Staphylococcus spp. E Klebsiella pneumoniae, isolados de tanque de refrigeração de leite, em cultura pura e associação", protocolo $n^{\circ} 758 / 2005$, utilizando coleta de leite bovino, sob a responsabilidade do Prof. Dr. Nilson Roberti Benites, está de acordo com os principios éticos de experimentação animal da Comissão de Bioética da Faculdade de Medicina Veterinária e Zootecnia da Universidade de São Paulo e foi aprovado "ad referendun".

(We certify that the Research "Study of colony form units in the milk of Staphylococcus spp. and Klebsiella pneumoniae, isolated from tank of milk refrigeration in pure culture and association", protocol number 758/2005, under the responsibility of Prof. Dr. Nilson Roberti Benites, agree with Ethical Principles in Animal Research adopted by Bioethic Commission of the Faculty of Veterinary Medicine and Zootechny of University of São Paulo and was approved "ad referendun", meeting).

São Paulo, 03 de novembro de 2005

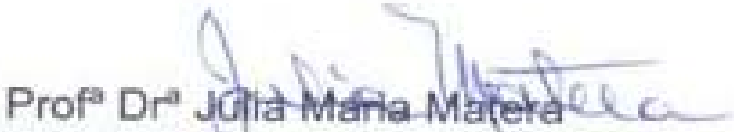

Presidente da Comissão de Bioética

FMVZIUSP 


\section{FOLHA DE AVALIAÇÃO}

Nome: FREITAS, Gisele Dias de

Título Comparação entre o crescimento de Unidades Formadoras de Colônias (UFC) de Staphylococcus spp. e Klebsiella pneumoniae e a sensibilidade destas cepas ao processo de pasteurização lenta

Dissertação apresentada ao Programa de Pós-Graduação em Epidemiologia Experimental e Aplicada à Zoonoses da Faculdade de Medicina Veterinária e Zootecnia da Universidade de São Paulo para obtenção do título de Mestre em Medicina Veterinária

Data:

\section{Banca Examinadora}

Prof. Dr. Instituição:

Assinatura: Julgamento:

Prof. Dr. Instituição:

Assinatura: Julgamento:

Prof. Dr. Instituição:

Assinatura: ulgamento: 


\section{DEDICATÓRIA}

À Deus que em todos os momentos de nossas vidas nos acompanha. 
Aos meus pais, Nelson Dias de

Freitas e Vera Lucia Mazucato de Freitas e ao meu irmão Neury Dias de Freitas pela lição, honestidade e apoio demonstrados a cada momento, que sempre deram força e base para seguir o meu caminho e alcançar meus objetivos. 
"Sozinho, você está mal acompanhado" 
"Se depender de mim, nunca ficarei completamente maduro, nem nas idéias, nem no estilo, mas sempre verde, incompleto, experimental"

Gilberto F reire 


\section{AGRADECIMENTOS}

Ao meu orientador Prof. Dr. Nilson Roberti Benites, pelo apoio, paciência, oportunidade, confiança e respeito dispensados durante o período de realização deste trabalho.

Agradecimento especial à Dra Priscila Ane Melville, por toda ajuda nesta dissertação.

Agradecimento especial ao Prof. Dr. Silvio Arruda Vasconcelos, Coordenador do Curso de Pós-graduação em Epidemiologia Experimental e Aplicada às Zoonoses, da FMVZ - USP pela dedicação incansável e amizade.

Agradecimento especial à Profạ. Drạ. Sonia Regina Pinheiro, pela incansável parceria e amizade.

Agradecimento especial ao Prof. Dr. Ricardo Augusto Dias, pela paciência, ajuda nas análises estatísiticas e pela amizade de todos os dias.

Agradecimento especial à Profa. Dra . Evelise Oliveira Telles Ramos e Silva, do Setor de Higiene Alimentar, VPS/FMVZ/USP, pelo esclarecimento e ajuda na metodologia deste trabalho e pela amizade.

Agradecimento especial aos colegas de Pós-graduação e laboratório, Clarice Yukami Minagawa, Sonia Sakata, Luís Ivan Martinhão Souto, Patrícia M. Ohara e Vanessa Zappa pelo companheirismo e amizade em cada momento da realização deste trabalho.

Aos funcionários e professores do VPS - FMVZ - USP pela companhia e conhecimento compartilhado

A todos os docentes e colegas de residência e mestrado do Departamento de Medicina Veterinária Preventiva e Saúde Animal (VPS) pelo incentivo e despertar para a pesquisa.

A todos os meus amigos, parentes e conhecidos, que de forma direta ou indireta acompanharam e torceram pela concretização deste projeto. 


\section{RESUMO}

FREITAS, G. D. Comparação entre o crescimento de Unidades Formadoras de Colônias (UFC) de Staphylococcus spp. e Klebsiella pneumoniae e a sensibilidade destas cepas ao processo de pasteurização lenta. [Comparison between the growth of Colony Form Units of Staphylococcus spp. and Klebsiella pneumoniae and the sensibility of these microorganisms to the process of slow pasteurization]. 2007. "88" f. Dissertação (Mestrado em Medicina Veterinária) - Faculdade de Medicina Veterinária e Zootecnia, Universidade de São Paulo, São Paulo, 2007.

Introdução: O leite pode ser considerado um dos alimentos mais completos por apresentar alto teor de proteínas e sais minerais, porém, também é considerado excelente meio de cultura para microrganismos. Objetivos: Identificar o número de UFC de Staphylococcus spp. e Klebsiella pneumoniae, cultivados isoladamente ou em associação, em leite integral estéril, a $6{ }^{\circ} \mathrm{C}, 27^{\circ} \mathrm{C}$ e $37^{\circ} \mathrm{C}$ e descrever a curva de morte térmica, quando submetidas ao processo de pasteurização lenta isoladamente ou em associação. Material e Métodos: Avaliação através da contagem das UFC, do comportamento de Staphylococcus spp. e K. pneumoniae, isoladas de tanque de refrigeração de leite, submetidas a temperaturas que simulam o leite em condições de refrigeração $\left(6^{\circ} \mathrm{C}\right)$, condições ambientais $\left(25^{\circ} \mathrm{C}\right)$ e na temperatura ideal de crescimento de patógenos mesófilos $\left(36^{\circ} \mathrm{C}\right)$. Avaliação da sensibilidade de Staphylococcus spp. e K. pneumoniae isoladas e em associações ao processo de pasteurização lenta. Resultados: Na escala 1 de Mac Farland a média de UFC de K. pneumoniae foi maior que a de Staphylococcus spp. A $6{ }^{\circ} \mathrm{C}$ as bactérias no leite, isoladas ou em associação crescem na mesma velocidade. A $25{ }^{\circ} \mathrm{C}$ a $\mathrm{K}$. pneumoniae cresce mais que o Staphylococcus spp. A $25{ }^{\circ} \mathrm{C} K$. pneumoniae associada ao Staphylococcus spp. cresce mais do que quando encontra-se isolada. A $36{ }^{\circ} \mathrm{C}$ K. pneumoniae associada ao Staphylococcus spp. cresce mais do que quando encontra-se isolada e ainda mais que a $25^{\circ} \mathrm{C}$. A pasteurização lenta foi efetiva, pois reduziu em no mínimo $90 \%$ as UFC no leite após 30 minutos a $65{ }^{\circ} \mathrm{C}$.

Conclusão: a medida que aumenta a temperatura, até $36{ }^{\circ} \mathrm{C}$, a Klebsiella pneumoniae apresenta crescimento superior ao Staphylococcus spp., a contaminação de leite por Klebsiella pneumoniae (contaminação ambiental) irá influenciar mais na qualidade do produto final, comparando-se à contaminação por Staphylococcus spp., oriundo de mastite e a interação de microrganismos altera a 
morte dos mesmos, recomendando-se que novos estudos sejam realizados para que se entenda melhor esse processo.

Palavras-Chave: Staphylococcus spp. Klebsiella pneumoniae. Comparação de Unidades Formadoras de Colônias (UFC). Pasteurização. Mastite 


\section{ABSTRACT}

FREITAS, G. D. Comparison between the growth of Colony Form Units of Staphylococcus spp. and Klebsiella pneumoniae and the sensibility of these microorganisms to the process of slow pasteurization. [Comparação entre 0 crescimento de Unidades Formadoras de Colônias (UFC) de Staphylococcus spp. e Klebsiella pneumoniae e a sensibilidade destas cepas ao processo de pasteurização lenta]. 2007. "88" f. Dissertação (Mestrado em Medicina Veterinária) - Faculdade de Medicina Veterinária e Zootecnia, Universidade de São Paulo, São Paulo, 2007.

Introduction: The milk can be considered one of the most complete food for its high contents of protein and minerals, but also it is considered an excellent medium of culture for microorganisms. Objective: To identify the number of the Colony Forming Units of Staphylococcus spp. and Klebsiella pneumoniae, in integral sterile milk, at different temperatures $\left(6^{\circ} \mathrm{C}, 27^{\circ} \mathrm{C}\right.$ e $\left.37^{\circ} \mathrm{C}\right)$ and to describe a thermal curve death, when submitted to the process of slow pasteurization isolated or in association. Materials and methods: Evaluation by counting of the colony forming units and the behavior of the Staphylococcus spp. and Klebsiella pneumoniae, isolated and in association occurred in the cooling tank, submitted to temperatures that simulate the conditions of milk in cooling $\left(6^{\circ} \mathrm{C}\right)$, environmental condition $\left(25^{\circ} \mathrm{C}\right)$ and the optimal temperature for the growth of microorganisms $\left(36^{\circ} \mathrm{C}\right)$. Evaluation of the sensibility of Staphylococcus spp. and Klebsiella pneumoniae isolated and in association during the pasteurization process. Results: In Scale 1 of Mac Farland the average of the colony form units of the $K$. pneumoniae was greater than the colony of Staphylococcus spp. At $6^{\circ} \mathrm{C}$ the microorganisms in the milk isolated or in association grew at the same speed. At $25^{\circ} \mathrm{C} K$. pneumoniae associated with Staphylococcus spp. grew more than when they were isolated. At $36^{\circ} \mathrm{C} K$. pneumoniae associated with Staphylococcus spp. grew more then when it was isolated and more than at $25^{\circ} \mathrm{C}$. So we can conclude that the slow pasteurization was effective, because it has reduced at least $90 \%$ of the colony form unity in the milk after 30 minutes at $65^{\circ} \mathrm{C}$. Conclusion: By raising the temperature up to $36^{\circ} \mathrm{C}$, a Klebsiella pneumoniae had a superior growth when compared with Staphylococcus spp.; the contamination of milk by Klebsiella pneumoniae (environmental contamination) influences the most the quality of the final product when compared to the contamination by Staphylococcus spp. from mastitis, we can also conclude that the interaction of microorganisms 
modify the death rate of them. New studies and researches are recommended to a deeper and better comprehension of this process.

Key Words: Staphylococcus spp. Klebsiella pneumoniae and Colony Forming Units (CFU). Pasteurization. Mastitis. 


\section{LISTA DE GRÁFICOS}

Gráfico 1 - Curva de Morte térmica da média de Unidades Formadoras de Colônia (UFC), durante o processo de pasteurização lenta para Klebsiella pneumoniae e Staphylococcus spp. pasteurizados isoladamente 61

Gráfico 2 - Curva de Morte térmica da média de Unidades Formadoras de Colônia (UFC) durante o processo de pasteurização lenta para Klebsiella pneumoniae e Staphylococcus spp. pasteurizados em associação 67 


\section{LISTA DE QUADRO}

Quadro 1 - Temperatura de armazenamento do Leite 


\section{LISTA DE FOTOS}

Foto 1 - Leite em temperatura ambiente de $30{ }^{\circ} \mathrm{C}$ na cidade de Dublin Irlanda, J ulho de 2006 25

Foto 2 - $\quad$ Foto mais aproximada de leite em temperatura ambiente de 30 ${ }^{\circ} \mathrm{C}$ na cidade de Dublin - Irlanda, J ulho de 2006 26

Foto 3 - Microscopia óptica de Staphylococcus spp. 31

Foto 4 - $\quad$ Semeadura em placa de Staphylococcus spp. em meio de cultura de ágar sangue.

Foto 5 - $\quad$ Microscopia óptica de Klebsiella pneumoniae. 33

Foto 6 - Semeadura em placa de Klebsiella pneumoniae. em meio de cultura PCA. 33 


\section{LISTA DE FIGURAS}

Figura 1 - Diluição da amostra de Klebsiella pneumoniae até $10^{-9} \mathrm{e}$ plaqueamento em duplicata 44

Figura 2 - Diluição da amostra de Staphylococcus spp. até $10^{-9} \mathrm{e}$ plaqueamento em duplicata 45

Figura 3 - Diluição da amostra de Staphylococcus spp. + Klebsiella pneumoniae até $10^{-9}$ e plaqueamento em duplicata 46

Figura 4 - Pasteurização, diluição e semeadura das sub-amostras de Staphylococcus spp. + Klebsiella pneumoniae 47

Figura 5 - Pasteurização, diluição e semeadura das sub-amostras de Staphylococcus spp. + Klebsiella pneumoniae 48 


\section{LISTA DE TABELAS}

Tabela 1 - Média, mediana e valores mínimos e máximos do número de Unidades Formadoras de Colônias por mililitro da Escala 1 de MacF arland. São Paulo, 2006/2007

Tabela 2 - Mediana e valores mínimo e máximo na contagem de Unidades Formadoras de Colônias de Klebsiella pneumoniae e Staphylococcus spp. isolados e em associação. São Paulo, 2006/2007

Tabela 3 - Crescimento de Unidades Formadoras de Colônias de cepas de Klebsiella pneumoniae isolada e em associação com Staphylococcus spp. em meio de cultura Mac Conkey e PCA na temperatura de crescimento de $6^{\circ} \mathrm{C} / 24 \mathrm{~h}$. São Paulo, 2006/2007

Tabela 4 - Crescimento de Unidades Formadoras de Colônias de cepas de Klebsiella pneumoniae isolada e em associação com Staphylococcus spp. em meio de cultura Mac Conkey e PCA na temperatura de crescimento de $25{ }^{\circ} \mathrm{C} / 24 \mathrm{~h}$. São Paulo, 2006/2007

Tabela 5 - Crescimento de Unidades Formadoras de Colônias de cepas de Klebsiella pneumoniae isolada e em associação com Staphylococcus spp. em meio de cultura Mac Conkey e PCA na temperatura de crescimento de $36^{\circ} \mathrm{C} / 24 \mathrm{~h}$. São Paulo, 2006/2007 
Tabela 6 - Média, mediana e valores mínimo e máximo do processo de pasteurização lenta, demonstrando a curva de morte térmica a cada cinco minutos (0 a 30 minutos), para Klebsiella pneumoniae isolada. São Paulo, 2006/2007 57

Tabela 7 - Resultados da média, mediana e valores mínimo e máximo do processo de pasteurização lenta, demonstrando a curva de morte térmica a cada cinco minutos (0 a 30 minutos), para Staphylococcus spp.isolado. São Paulo, 2006/2007 59

Tabela 8 - Resultados da média, mediana e valores mínimo e máximo do processo de pasteurização lenta, demonstrando a curva de morte térmica a cada cinco minutos (0 a 30 minutos), para Klebsiella pneumoniae associada à Staphylococcus spp. São Paulo, 2006/2007

Tabela 9 - Resultados da média, mediana e valores mínimo e máximo do processo de pasteurização lenta, demonstrando a curva de morte térmica a cada cinco minutos (0 a 30 minutos), para Staphylococcus spp. associado à Klebsiella pneumoniae. São Paulo, 2006/2007 65

Tabela 10 -Comparação entre 0 processo de pasteurização quando os microrganismos são submetidos ao processo isoladamente e em associação através do teste não paramétrico de Kruskal-Wallis. São Paulo, 2006/2007 68

Tabela 11 - Representação da função que mais se adequou a distribuição espacial dos resultados no processo de pasteurização lenta para Klebsiella pneumoniae e Staphylococcus spp, isolados e em associação. São Paulo, 2006/2007 


\section{LISTA DE ABREVIATURAS E SIGLAS}

$\begin{array}{ll}\text { K. pneumoniae } & \text { Hora } \\ \mathrm{mcg} & \text { Klebsiella pneumoniae } \\ \mathrm{mcL} & \text { Micrograma } \\ \mathrm{mg} & \text { Microlitro } \\ \mathrm{mL} & \text { Miligramas } \\ \mathrm{p} & \text { Mililitro } \\ \mathrm{sp} & \text { Página } \\ \mathrm{spp} & \text { Espécie } \\ \mathrm{U} . \mathrm{F} . \mathrm{C} & \text { Espécies } \\ \mathrm{n}^{\circ} & \text { Unidades Formadoras de Colônias } \\ \% & \text { Número } \\ { }^{\circ} \mathrm{C} & \text { Porcentagem } \\ \mathrm{NMP} & \text { Graus Celsius } \\ \end{array}$




\section{SUMÁRIO}

1 INTRODUÇÃO 24

2 REVISÃO DE LITERATURA 28

3 OBJETIVOS 37

3.1 Objetivos específicos 37

4 MATERIAIS E MÉTODOS 40

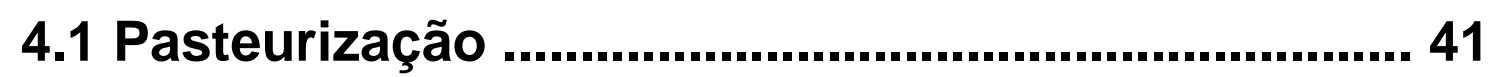

4.1.1 Controle do processo de pasteurização ............ 42

4.1.2 Fosfatase alcalina ................................................. 42

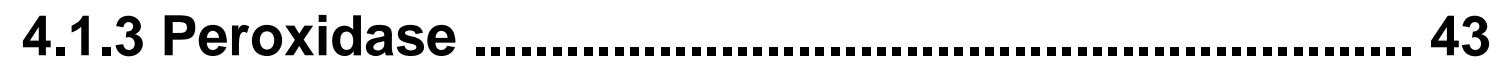

5 RESULTADOS ......................................................... 50

5.1 Resultados da pasteurização ................................. 56

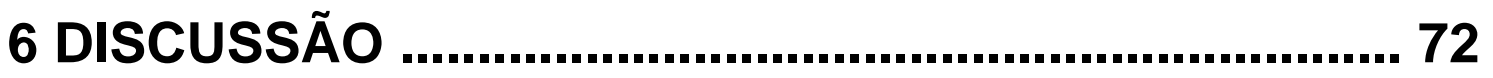

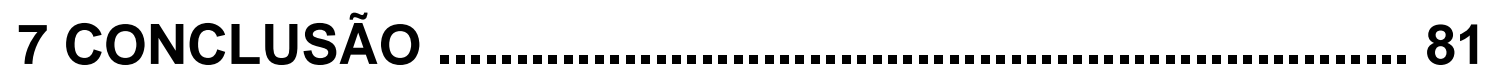

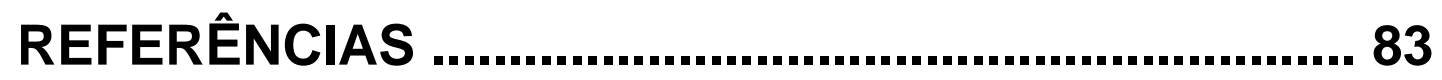


INTRODUÇÃO 


\section{INTRODUÇÃO}

A qualidade dos produtos alimentares é, hoje, uma das maiores preocupações tanto no ramo acadêmico e científico, onde uma grande variedade de projetos vem sendo desenvolvidos com o objetivo de averiguar a qualidade dos alimentos que chegam à mesa do consumidor, quanto na própria população que a cada dia mais se preocupa com a alimentação e com a qualidade do alimento que ingere ou oferece a sua família.

Entretanto muitas mudanças ainda necessitam ser realizadas, dentre elas, vários hábitos alimentares e culturais que podem provocar sérios danos à saúde dos consumidores. Estes costumes não se restringem apenas ao Brasil; nas duas fotos 1 e 2 a seguir, é possível visualizar uma prática extremamente difundida na população européia, onde o entregador de leite deixa os galões do lado de fora da porta do consumidor, a temperatura ambiente, até que este o resolva recolher, deixando 0 produto em temperatura inadequada onde pode ocorrer a multiplicação de diferentes tipos de microrganismos existentes no leite pasteurizado.

No Brasil, a maior dificuldade encontrada, principalmente entre a população menos urbana, é a idéia de que os produtos oriundos de sítios ou pequenas propriedades, onde não há qualquer tipo de inspeção sanitária ou controle de qualidade, sejam os produtos de melhor qualidade e os produtos mais "puros", porque não passam por qualquer tipo de industrialização.

Dentre estes produtos, pode-se destacar o mercado ilegal de leite cru, onde se acredita que mais da metade do leite consumido no Brasil seja desprovido de qualquer tipo de inspeção ou controle de qualidade, deixando claro o grande risco ao qual a população que utiliza este produto está exposta.

Quando se pesquisa a microbiota encontrada no leite é possível dividir os microrganismos encontrados em dois grupos. Aqueles que são originários de contaminação ambiental e aqueles oriundos de processos de mastite. Dentro destes dois grupos os principais microrganismos encontrados são os Staphylococcus spp. e as Klebsiella spp. 
Através das informações onde se relata que os microrganismos responsáveis pelo maior número de casos de mastites subclínica, é o Staphylococccus aureus e que o responsável pelo maior número de casos de mastites clínica é a Klebsiella pneumoniae, foi analisado neste trabalho, se existe alguma forma de interação entre os Staphylococcus aureus e as Klebsiella pneumoniae que possam causar algum tipo de supressão ou alteração no crescimento de um ou de ambos os microrganismos quando inseridos em um mesmo meio de cultura, o leite integral estéril, e oferecido-Ihes as mesmas condições de crescimento e se o processo de pasteurização lenta seria eficaz na destruição destes microrganismos.

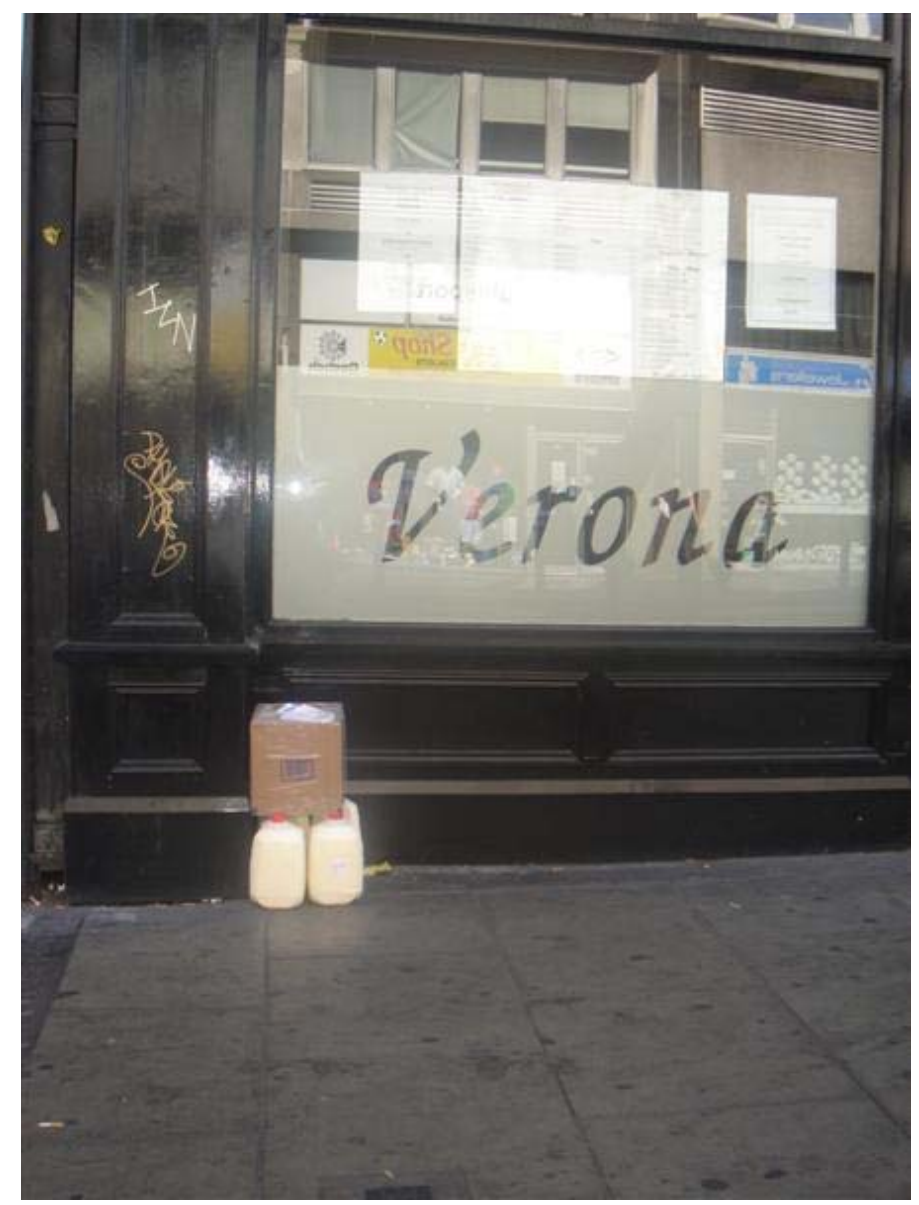

Foto 1 - Leite em temperatura ambiente de $30{ }^{\circ} \mathrm{C}$ na cidade de Dublin - República da Irlanda, J ulho de 2006 


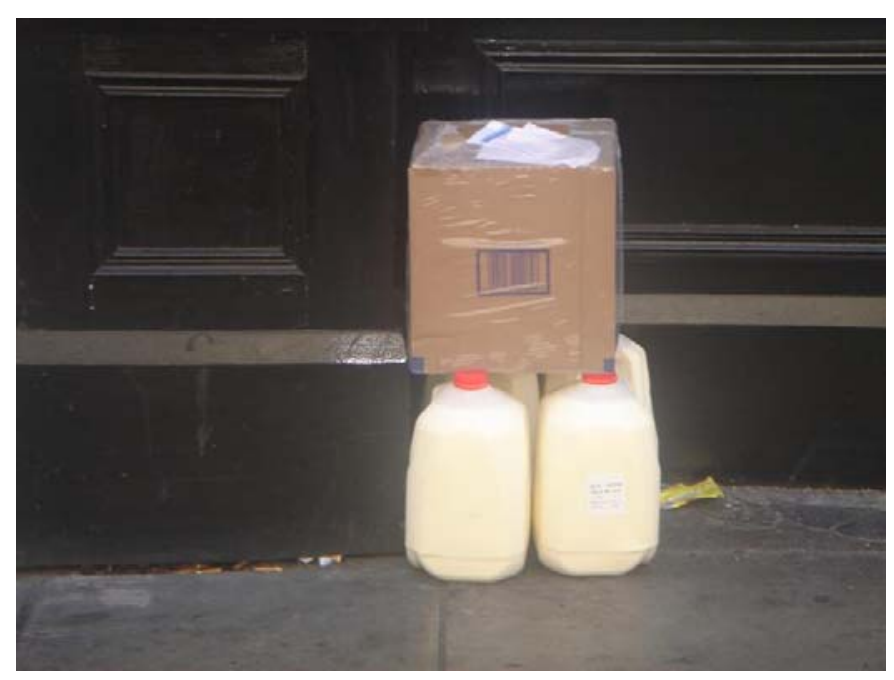

Foto 2 - Foto mais aproximada de leite em temperatura ambiente de $30{ }^{\circ} \mathrm{C}$ na cidade de Dublin - República da Irlanda, J ulho de 2006 
REVISÃO DE LITERATURA 


\section{REVISÃO DE LITERATURA}

Segundo o Regulamento de Inspeção Industrial e Sanitária de Produtos de Origem Animal - RIISPOA, artigo 475, "entende-se por leite, sem outras especificações, o produto oriundo da ordenha completa, ininterrupta, em condições de higiene, de vacas sadias, bem alimentadas e descansadas" (BRASIL, 1997).

Do ponto de vista biológico o leite pode ser considerado um dos alimentos mais completos por apresentar, entre outras características, alto teor de proteínas e sais minerais. Porém, também é considerado excelente meio de cultura, podendo ser facilmente contaminado por muitos grupos de microrganismos que encontram ótimas condições para multiplicação (ZOCCHE et al., 2002). Alguns desses microrganismos podem estar presentes no momento em que o leite é ordenhado. Outros são incorporados ou pelo ordenhador, utensílios mal higienizados ou mesmo pelo meio ambiente (MENDONÇA et al., 2005).

A obtenção de leite de boa qualidade depende de vários fatores como o estado sanitário do rebanho, as propriedades genéticas dos animais, a higiene do local, a qualidade da água utilizada na propriedade, as condições de exploração, o clima, as instalações, a alimentação, a mão-de-obra, as políticas comerciais e a sanidade do rebanho (AMARAL et al., 2003).

Embora o Brasil seja o sexto produtor de leite do mundo e a taxa de crescimento aumente $4 \%$ ao ano (EMBRAPA, 2003), todos os fatores acima mencionados, influenciam diretamente na receita final do produtor.

Comparando-se a produção leiteira brasileira com a mundial, em relação à quantidade e a qualidade do leite produzido por animal, é fácil observar que muitas medidas ainda devem ser tomadas para que esta atividade seja mais lucrativa e produtiva (VOLTOLINI et al., 2001).

Um dos maiores problemas dos produtores de leite é a mastite, uma enfermidade da glândula mamária que se caracteriza por processo inflamatório, quase sempre decorrente da presença de microrganismos infecciosos, interferindo diretamente na função do órgão, uma vez que uma vaca com mastite tem sua 
produtividade de leite diminuída, podendo chegar a níveis de perda entre 15 a 20\% em relação à produção láctea normal (INTERVET, 2005).

Segundo Voltolini et al. (2001), a mastite é considerada a doença que mais onera a produção de ıeite, acarretando graves prejuízos econômicos aos produtores e à indústria leiteira, entretanto, muitos produtores ainda não se preocupam com este problema, talvez por não saberem das perdas decorrentes dessa enfermidade, um dos motivos da altíssima incidência da doença no rebanho brasileiro.

Além dos prejuízos contabilizados pela redução na produção, descarte do leite de vacas em tratamento, custos com medicamentos, gastos com assistência técnica e reposição de vacas e do tempo extra, perdido no manejo e na aplicação de medicamentos (VOLTOLINI et al., 2001), as mastites depreciam a qualidade nutritiva do leite, com a diminuição dos teores de açúcares, proteínas e minerais como a lactose, caseína, gordura, cálcio, fósforo e aumento significativo de imunoglobulinas, cloretos e lipases, tornando o produto inapropriado para ser consumido ou utilizado para fabricação de seus derivados como iogurtes e queijos, sem considerar os prejuízos causados pela condenação do leite na plataforma das usinas (INTERVET, 2005).

Segundo Barbalho e Mota (2001), os principais microrganismos causadores de mastite bovina podem ser divididos em cinco grupos: cocos Gram-positivos, bactérias Gram-negativas, corinebactérias e Actinomyces, Mycoplasma e outros como Nocardia spp., Prototheca spp. e leveduras; entretanto os cocos Grampositivos constituem o principal grupo, responsável por mais de $90 \%$ das ocorrências, sendo o Staphylococccus aureus e Streptococcus agalactiae as espécies mais freqüentes.

De acordo com Voltolini et al. (2001), os microrganismos dos cinco grupos acima descritos, podem ser divididos em dois grupos, ou seja, aqueles que provocam a mastite infecciosa, normalmente, com sintomatologia subclínica e são isolados no úbere, podendo ser transmitidos para outras vacas no momento da ordenha, e aqueles que são isolados do meio ambiente infectando a vaca antes ou após a ordenha, normalmente produz mastite com sintomatologia clínica.

De acordo com Reis, Silva e Brescia et al. (2003), a denominação de mastite subclínica é utilizada quando não há alterações visíveis na glândula mamária, porém 
o leite apresenta alta contagem de células somáticas (CCS), o que caracteriza uma inflamação na glândula mamária. Normalmente, este tipo de mastite tem como agente(s) etiológico(s) os seguintes microrganismos: Staphylococcus aureus, Staphylococcus coagulase-negativo, Bacillus spp., Corynebacterium bovis, Streptococcus uberis, Streptococcus dysgalactiae, Pseudomonas aeruginosa e Escherichia coli.

Enquanto que Ribeiro etal. (2003), classificam a mastite como clínica quando é possível observar alterações na glândula mamária tais como: edema, endurecimento, dor, grumos, pus, ou qualquer alteração das características do leite. As mastites clínicas normalmente são causadas por bactérias provenientes de contaminação ambiental, e normalmente são causadas por Klebsiella sp., Escherichia coli, Enterobacter sp dentre outros (INTER VET, 2005).

De acordo com Zia et al. (1987), as enterobactérias causam mastite com forte sintomatologia clínica, pois produzem enterotoxinas que induzem a severa reação inflamatória nas glândulas mamárias.

De acordo com Salasia et al. (2004) e Wilson, Gonçalvez e Das et al. (1997), os estafilococos, principalmente o Staphylococcus aureus são mundialmente reconhecidos como os maiores patógenos causadores de mastite, principalmente a subclínica, em rebanhos leiteiros provocando a perda de milhões de dólares por ano (aproximadamente $\$ 170,00$ por animal em cada lactação).

De acordo com Barbalho e Mota (2001), o gênero Staphylococcus pertence à família Micrococaceae, são cocos Gram-positivos, catalase positivos, que tendem a formar agrupamentos semelhantes a cachos de uva (Fotos 3 e 4). São amplamente distribuídos na natureza e fazem parte da microbiota normal da pele e mucosas de mamíferos e aves. Tradicionalmente são divididos em duas categorias: coagulase positivos e coagulase negativos (MENDONÇA et al., 2005). Essa divisão é baseada na capacidade de coagular o plasma, que é uma propriedade considerada como importante marcador de patogenicidade dos estafilococos (MARTINS, 1999). 


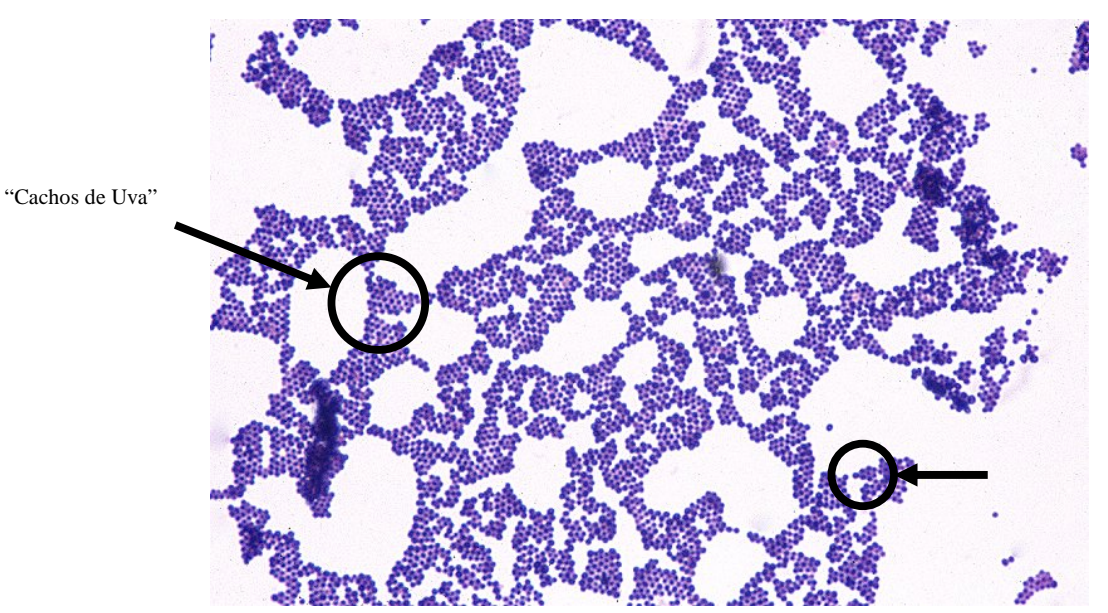

Fonte: SOUTO, L. I. M. (2006)

Foto 3 - Microscopia óptica de Staphylococcus spp

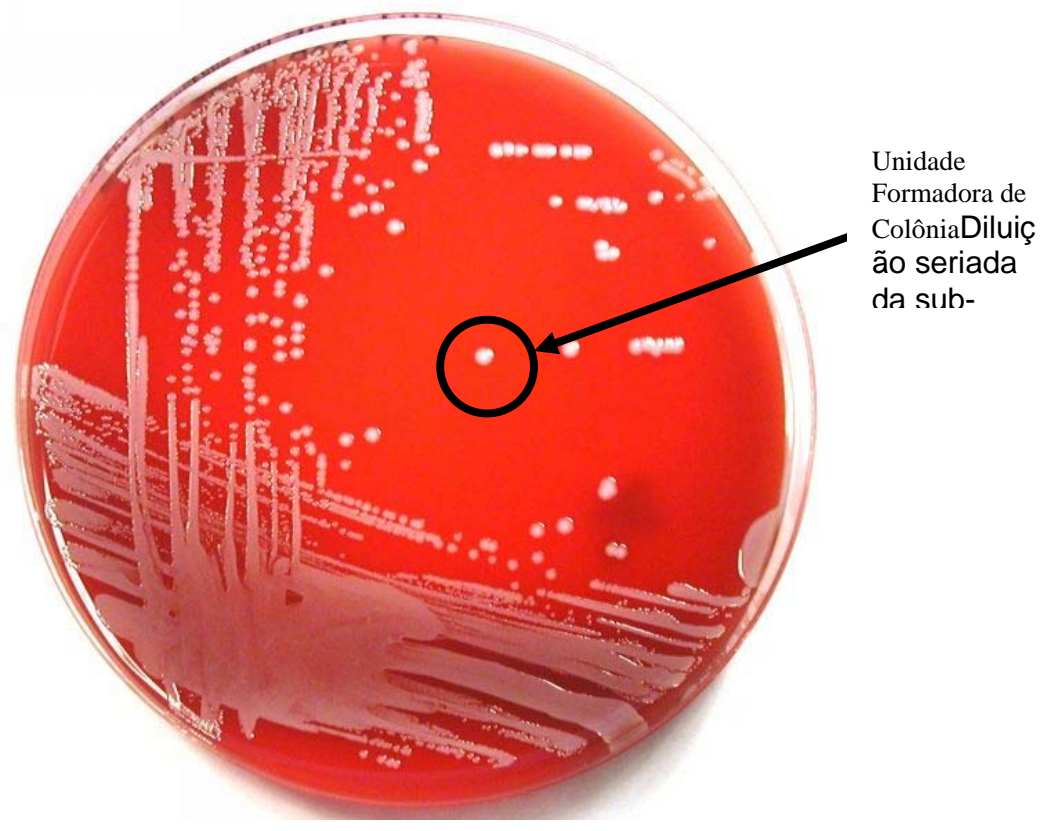

Fonte: SOUTO, L. I. M. (2006)

Foto 4 - Semeadura em placa de Staphylococcus spp. em meio de cultura de ágar sangue 
Quanto à patogenicidade, os estafilococos, principalmente o Staphylococcus aureus, é o agente mais frequentemente isolado de infecções piogênicas. Estas infecções podem se localizar na pele ou em regiões mais profundas, como a glândula mamária. Além de infecções piogênicas, este agente pode causar vários tipos de intoxicações, seja na vigência de um processo infeccioso ou não (MARTINS, 1999).

Segundo Silva e Gandra (2004), além de infecções, o Staphylococcus aureus, é a espécie mais relacionada a casos de surtos de intoxicação alimentar, devido à capacidade da maioria de suas cepas produzirem enterotoxinas. Estas toxinas são proteínas extracelulares, com baixo peso molecular, hidrosolúveis e possuem uma característica de extrema relevância; são termoestáveis, sendo capazes de resistir a processos térmicos como a pasteurização e a ultra pasteurização.

Quando ocorre a intoxicação, os sintomas aparecem, em média, após 4 horas da ingestão do alimento contaminado e é caracterizado por vômitos, náuseas, diarréia, contrações abdominais e dores de cabeça muito fortes. Geralmente duram entre 24 e 48 horas e 0 índice de mortalidade da doença não é alto (SILVA et al., 2000).

Como descreveram Amaral et al. (2003) os maus hábitos na ordenha e no processamento do leite, levam contaminações ao produto como material fecal ou microrganismos que podendo causar danos à saúde do consumidor quando ingerirem 0 alimento contaminado.

Segundo Jasper, Dellinger e Bushnell et al. (1975), o acompanhamento veterinário com a intenção de diminuir a incidência de mastites nos rebanhos e a utilização de programas de pré-dipping e pós-dipping tem diminuído consideravelmente, os problemas com Staphylococcus spp. e com Streptococcus agalactiae, mas, não tem efeito significativo quanto à prevenção da contaminação por Streptococcus uberis e por coliformes. Além do que, de acordo com o autor, rebanhos leiteiros relativamente livres dos Staphylococcus spp. e Streptococcus agalactiae tendem a ser, mais susceptíveis as infecções por coliformes.

Quando se pesquisa mastites provocadas por coliformes (28\% dos casos), observa-se, que em aproximadamente $52 \%$ dos casos podem ser isolados Klebsiellas pneumoniae, sendo que normalmente, os animais com este padrão de mastite são daqueles rebanhos onde a higienização da cama e das instalações da propriedade é precária. Isso acontece, pois, ao contrário do que ocorre com a 
maioria dos estreptococos e dos estafilococos, onde o maior índice de transmissão da infecção é entre os animais do rebanho, os coliformes alcançam os animais através do contato com contaminações do próprio meio ambiente (JASPER, DELLINGER; BUSHNELL et al., 1975).

Segundo Trabulsi e Campos (1999) as Klebsiellas spp. pertencem à família das enterobactérias, são bacilos Gram-negativos, encontrados amplamente na natureza, como habitantes dos intestinos do homem e dos animais, como membros da microbiota normal ou como agentes de infecção (Fotos 5 e 6).

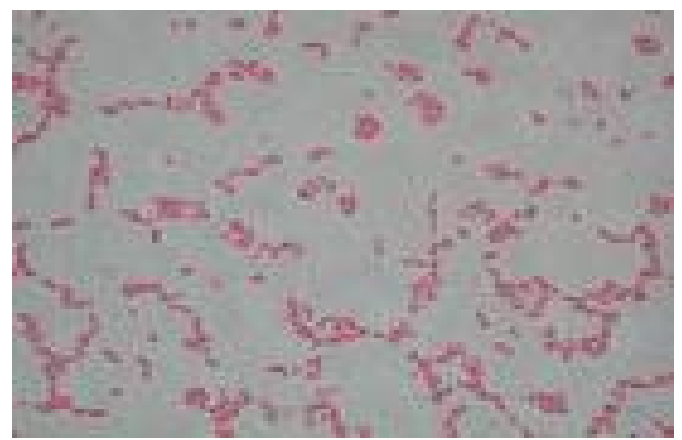

Fonte: FREITAS, G. D. (2007)

Foto 5 - Microscopia óptica de Klebsiella pneumoniae

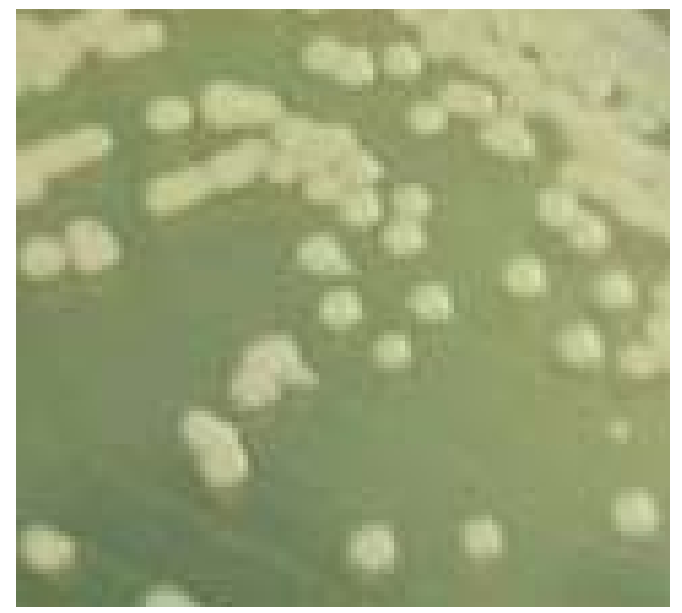

Fonte: FREITAS, G. D. (2007)

Foto 6 - Semeadura em placa de Klebsiella pneumoniae. em meio de cultura PCA 
De acordo com Nonnecke e Newbould (1984), as bactérias do gênero Klebsiella, causam mastites nos animais com diferentes graus de gravidade, sendo que, grandes números desses microrganismos estão envolvidos com problemas nas glândulas mamárias, principalmente naqueles rebanhos onde se utiliza serragem ou lascas de madeira como cama para os animais.

Kikuchi et al. (1995), relatam que os animais que desenvolvem mastite tendo a K. pneumoniae como agente etiológico, normalmente estão com baixa imunidade, o que facilita para que o prognóstico de recuperação nesses casos seja desfavorável, ou com grande chance de perda da habilidade de produzir leite na glândula mamária afetada.

A quantidade e as espécies de microrganismos presentes no leite cru, imediatamente após a ordenha refletem diretamente a contaminação microbiana ocorrida durante a produção. Quando o leite deixa a fazenda, a sua microbiota é determinada pela relação tempo/temperatura na qual ele foi mantido e estocado. Quando o leite é mantido a $4^{\circ} \mathrm{C}$ ou menos, previne-se a multiplicação bacteriana por 24h (ROBINSON, 1989).

A temperatura constitui um dos principais parâmetros responsáveis pelo controle do crescimento e da velocidade de multiplicação microbiana. A temperatura exerce ação seletiva sobre os microrganismos do alimento, retardando o seu crescimento se for suficientemente baixa. Para se manter a qualidade do leite após a ordenha, deve-se tomar uma série de cuidados, como proceder à pasteurização, por exemplo (BEHMER, 1991).

Segundo Alterthum e Carvalhal (1999) o método mais empregado para matar microrganismos é o calor, por ser eficaz, barato e prático. Do ponto de vista microbiológico são considerados mortos quando perdem, de forma irreversível, a capacidade de se multiplicar.

De acordo com Behmer (1991), as fases para o tratamento do leite após a ordenha são:

- Filtração: tem como finalidade eliminar as impurezas grosseiras, que eventualmente possam cair no leite.

. Resfriamento: o leite ordenhado possui a temperatura do animal, ou seja, aproximadamente $35^{\circ} \mathrm{C}$, temperatura ideal para que grande parte dos microrganismos possa se multiplicar. A função do resfriamento até $4^{\circ} \mathrm{C}$ é retardar a multiplicação microbiana, prolongando o tempo de vida do produto. 0 leite cru 
resfriado não deve ser armazenado por mais de 24 horas, pois existem microrganismos que se desenvolvem em baixas temperaturas.

- Tratamento térmico: os mais utilizados são a fervura e a pasteurização. Louis Pasteur, em 1864, desenvolveu um método de prevenção da perda da perda da qualidade dos vinhos, destruindo pelo calor bactérias capazes de deteriorar esta bebida. Tal método, posteriormente, foi aplicado ao tratamento do leite para eliminar possíveis patógenos veiculados por este alimento, o qual recebeu o nome de pasteurização.

No Brasil pode ser empregada a pasteurização de curta duração, que consiste no aquecimento do leite a $72-75^{\circ} \mathrm{C}$ por 15 a 20 segundo, e pasteurização lenta, a qual consiste no aquecimento do leite a $62-65^{\circ} \mathrm{C}$ por 30 minutos. Imediatamente após o aquecimento em ambos os procedimentos o leite deve ser resfriado entre 2 a $5^{\circ} \mathrm{C}$ (BRASIL, 1980).

Assim como relata Alterthum e Carvalhal (1999) a pasteurização destrói as bactérias patogênicas, eventualmente transmissíveis pelo leite e reduz o número de todos os microrganismos presentes.

Através das informações onde se relata que os microrganismos responsáveis pelo maior número de intoxicações alimentares e casos de mastites subclínica, é o Staphylococccus aureus e que o responsável pelo maior número de casos de mastites clínica é a Klebsiella pneumoniae, foi analisado neste trabalho, se existe alguma forma de interação entre os Staphylococcus spp. e as Klebsiellas pneumoniae que possam causar algum tipo de supressão ou alteração no crescimento de um ou de ambos os microrganismos quando inseridos em um mesmo meio de cultura, o leite integral estéril, e oferecido-lhes as mesmas condições de crescimento e se o processo de pasteurização lenta é eficaz na destruição destes microrganismos. 
OBJETIVOS 


\section{OBJETIVOS GERAIS}

Avaliar a interatividade entre Staphylococcus spp e Klebsiella pneumoniae, isolados de leite mastítico e de tanques de resfriamento, quando analisados os mecanismos de interferência, na multiplicação de cada microrganismos separadamente e juntos, para avaliar a "inibição" ou "interferência" de crescimento por parte das espécies envolvidas, quando cultivadas, num mesmo meio de cultura, 0 leite integral estéril, em três diferentes temperaturas; $6^{\circ} \mathrm{C}$ (temperatura de refrigeração), $25^{\circ} \mathrm{C}$ (temperatura ambiente) e $36^{\circ} \mathrm{C}$ (temperatura ideal de crescimento dos microrganismos em estudo).

Avaliar o efeito da pasteurização lenta nas colônias de Staphylococcus e Klebsiella pneumoniae, quando submetidas ao processo isoladamente e em associação.

\subsection{OBJETIVOS ESPECÍFICOS}

- Identificar o número de unidades formadoras de colônia (UFC) de Staphylococcus spp., quando cultivadas isoladamente, em leite estéril, em três diferentes temperaturas $\left(6^{\circ} \mathrm{C}, 25^{\circ} \mathrm{C}\right.$ e $\left.37^{\circ} \mathrm{C}\right)$.

- Identificar o número de unidades formadoras de colônia (UFC) de Klebsiella pneumoniae, quando cultivadas isoladamente, em leite estéril, em três diferentes temperaturas $\left(6^{\circ} \mathrm{C}, 25^{\circ} \mathrm{C}\right.$ e $\left.37^{\circ} \mathrm{C}\right)$.

- Identificar o número de unidades formadoras de colônia (UFC) de Staphylococcus ssp., e de Klebsiella pneumoniae quando cultivadas juntas, em leite integral estéril, em três diferentes temperaturas $\left(6^{\circ} \mathrm{C}, 25^{\circ} \mathrm{C}\right.$ e $\left.37^{\circ} \mathrm{C}\right)$.

- Descrever a curva de morte térmica das cepas de Klebsiella pneumoniae e Staphylococcus spp. quando submetidas ao processo de pasteurização lenta. 
- Descrever se há diferença na curva de morte térmica quando os microrganismos são pasteurizados isolados ou em associação. 
MATERIAL E MÉTODOS 


\section{MATERIAL E MÉTODO}

Este trabalho foi realizado no laboratório de doenças infecciosas do Departamento de Medicina Veterinária Preventiva e Saúde Animal (VPS) da Faculdade de Medina Veterinária e Zootecnia da Universidade de São Paulo, no período de agosto de 2005 a dezembro de 2007.

Os microrganismos utilizados foram: Klebsiella pneumoniae e Staphylococcus spp., isolados de amostras de leite de tanque de refrigeração de propriedades de exploração de leite cru, tipo A, B e C. As culturas foram feitas pela semeadura dos leites, em meios sólidos contendo ágar-sangue $(8 \%$ de sangue desfibrilado de ovino), distribuídos em Placa de Petri e incubados a $36^{\circ} \mathrm{C}$, e a leitura realizada 24 horas após a semeadura. As colônias selecionadas foram coradas pelo método de Gram, para diferenciar as bactérias em Gram negativas (Klebsiella spp.) das Gram positivas (Staphylococcus spp).

Para os microrganismos já previamente isolados e identificados, foram preparadas duas suspensões na Escala Mac Farland (suspensão de sulfato de bário, escala 1,0 ) sendo a primeira com uma linhagem de Klebsiella pneumoniae (Figura 1) e a segunda com estirpe de Staphylococcus spp. (Figura 2).

A partir destas amostras, foi colhida uma alíquota de $0,5 \mathrm{~mL}$ da solução de Klebsiella pneumoniae e $0,5 \mathrm{~mL}$ da solução de Staphylococcus spp., que foram adicionadas respectivamente em tubos de ensaios contendo $4,5 \mathrm{~mL}$ de leite integral estéril cada um (Figuras 1 e 2). Em outro tubo de ensaio contendo $4 \mathrm{~mL}$ de leite integral estéril, foi adicionado $0,5 \mathrm{~mL}$ da suspensão de Klebsiella pneumoniae e 0,5 $\mathrm{mL}$ da solução de Staphylococcus spp. (Figura 3). Todos os tubos foram armazenados, por 24 horas, em três temperaturas diferentes, $6^{\circ} \mathrm{C}, 25^{\circ} \mathrm{C}$ e $36^{\circ} \mathrm{C}$. Foi realizada após 24 horas a diluição, até $10^{-9}$ das soluções de Klebsiella pneumoniae e Staphylococcus spp. e Klebsiella pneumoniae + Staphylococcus spp. Uma alíquota de 0,1 mL foi colhida de cada diluição para cultivo (utilizando-se a técnica de spread plate ou, espalhamento em placas), em ágar para contagem padrão (PCA - Plate Count Agar) e Mac Conkey (quando cultivadas amostras de Klebsiella pneumoniae e Staphylococcus spp em associação), com incubação a $36^{\circ} \mathrm{C}$ por um período de 24 horas, e após este período foram contadas as UFC/mL. Este processo foi realizado 14 vezes. 
A partir das culturas obtidas e armazenadas pelo tempo e temperaturas acima descritos, todas as placas que tiveram UFC/mL em número menor ou igual a 250 foram contadas e o resultado anotado.

Em todas as etapas experimentais, sem exceção, a técnica asséptica foi valorizada e os testes formam efetuados em duplicatas.

\subsection{PASTEURIZAÇÃO}

Para os microrganismos já previamente isolados e identificados, foram preparadas duas suspensões na Escala Mac Farland 1 sendo a primeira com uma linhagem de Klebsiella pneumoniae e a segunda com estirpe de Staphylococcus spp. A partir destas amostras, foram colhidas alíquotas de $1 \mathrm{~mL}$ da solução de Klebsiella pneumoniae e $1 \mathrm{~mL}$ da solução de Staphylococcus spp., que foram adicionadas respectivamente em 6 tubos de ensaios contendo $9 \mathrm{~mL}$ de leite integral estéril cada um; em outros 6 tubos de ensaio foram adicionados $1 \mathrm{~mL}$ de Klebsiella pneumoniae e $1 \mathrm{~mL}$ Staphylococcus spp. em $8 \mathrm{~mL}$ de leite integral estéril. Estes processos foram repetidos 7, 9 e 10 vezes respectivamente, de acordo com a disponibilidade de Unidades Formadoras de Colônias, viáveis, de cada microrganismo.

Com o intuito de agilizar o processo de aquecimento do leite e mimetizar o processo natural de pasteurização lenta feita em tanques, foi realizada uma etapa de pré-aquecimento dos tubos em banho-maria a $85^{\circ} \mathrm{C}$ até que fosse atingida a temperatura de $65^{\circ} \mathrm{C}$.

Ao atingir a temperatura de $65^{\circ} \mathrm{C}$, retirou-se para análise a sub-amostra 0 (zero), que foi colocada em banho de gelo e o restante das sub-amostras foram transferidas ao banho-maria a $65^{\circ} \mathrm{C}$, para manutenção da temperatura, iniciando-se a contagem do tempo de pasteurização.

A sub-amostra 0 (zero) foi utilizada para avaliar esta etapa de aquecimento do leite, até que atingisse a temperatura desejada de $65^{\circ} \mathrm{C}$ (Figura 4).

Alcançando-se o tempo desejado de 5, 10, 15, 20, 25 e 30 minutos, os respectivos tubos eram retirados do banho-maria e colocados em um banho de gelo para cessar o efeito térmico sobre as células. A cada temperatura, uma 
alíquota de 0,1 $\mathrm{mL}$ foi semeada ao meio de cultura PCA, utilizando a técnica de spread plate ou espalhamento em placa (Figura 5 ).

Em todas as etapas experimentais, sem exceção, a técnica asséptica foi valorizada e os testes formam efetuados em duplicatas

\subsubsection{Controle do processo de pasteurização}

Foram colocados no banho-maria mais 4 tubos com leite integral não inoculado, e com o mesmo volume de leite das sub-amostras, desde o aquecimento até 0 fim do tratamento térmico. Em um desses tubos foi colocado um termômetro, com o intuito de controlar a temperatura, tomando-se o cuidado para que o bulbo do termômetro não entrasse em contato com as paredes do tubo. Os outros tubos foram empregados para pesquisa das enzimas fosfatase alcalina (1 tubo) e peroxidase (2 tubos) (BRASIL, 1981).

Para as análises estatísticas foram utilizados os softwares Graphpad Instat, Epinfo 6.04d, Microsoft Office ${ }^{\circledR}$ versão 2003 e SPSS 9.0. 0 teste estatístico utilizado foi Kruskal Wallis, Intervalo de Confiança de 95\%, com nível de significância (valor de $p<0,05$ ) e foi realizado análises para ajuste de função (Quadrática, Cúbica, Linear).

\subsubsection{Fosfatase Alcalina}

Após 0 tratamento térmico, utilizou-se 0 teste colorimétrico da Laborclin para determinação qualitativa da enzima fosfatase alcalina no leite. É um teste que consiste na mistura $2 \mathrm{~mL}$ de amostra de leite para $1 \mathrm{~mL}$ de reagente e posterior incubação em banho-maria a $37^{\circ} \mathrm{C}$ por 10 minutos. A presença de fosfatase alcalina é caracterizada pela coloração amarela na mistura. 


\subsubsection{Peroxidase}

A verificação qualitativa da enzima peroxidase foi realizada seguindo-se os procedimentos recomendados pelos Métodos Analíticos para o controle de Produtos de Origem Animal e seus Ingredientes - Métodos Físico-Químicos, do Laboratório Nacional de Referência Animal - LANARA (BRASIL, 1981). 
Suspensão de Klebsiella pneumoniae em salina. Escala

$1: 10$ após ter permanecido $24 \mathrm{~h}$ em $6{ }^{\circ} \mathrm{C}, 25^{\circ} \mathrm{C}$ e $36^{\circ} \mathrm{C}$

Amostra de leite integral estéril de $4,5 \mathrm{ml}$

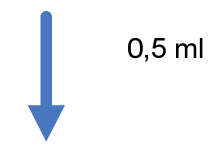

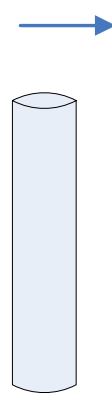

$10^{-1}$

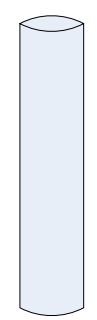

$10^{-2}$

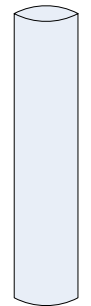

$10^{-3}$

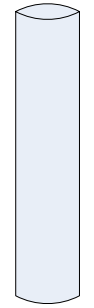

$10^{-4}$

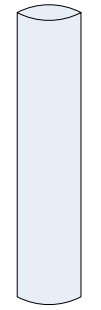

$10^{-5}$

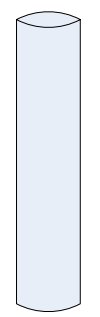

$10^{-6}$

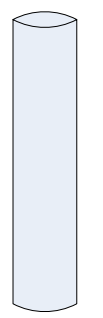

$10^{-7}$

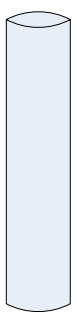

$10^{-8}$

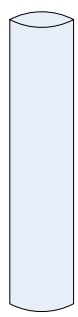

$10^{-9}$
0,1 ml em ágar PCA em duplicata

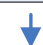

$36{ }^{\circ} \mathrm{C}$ em estufa microbiológica

$\downarrow$

Contar UFC/ml

Figura 1 - Diluição da amostra de Klebsiella pneumoniae até $10^{-9}$ e plaqueamento em duplicata 

Suspensão de Staphylococcus spp. em salina. Escala 1:10 após ter permanecido $24 \mathrm{~h}$ em $6{ }^{\circ} \mathrm{C}, 25^{\circ} \mathrm{C}$ e $36^{\circ} \mathrm{C}$

Amostra de leite integral estéril de $4,5 \mathrm{ml}$

$0,5 \mathrm{ml}$

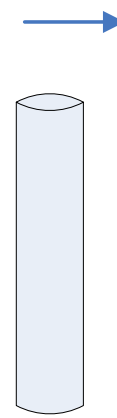

$10^{-1}$

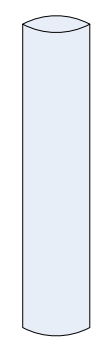

$10^{-2}$

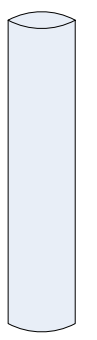

$10^{-3}$

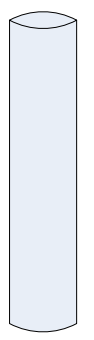

$10^{-4}$

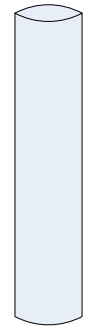

$10^{-5}$

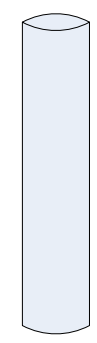

$10^{-6}$

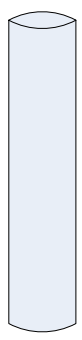

$10^{-7}$

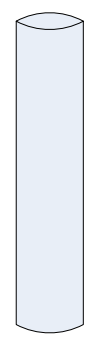

$10^{-8}$ 


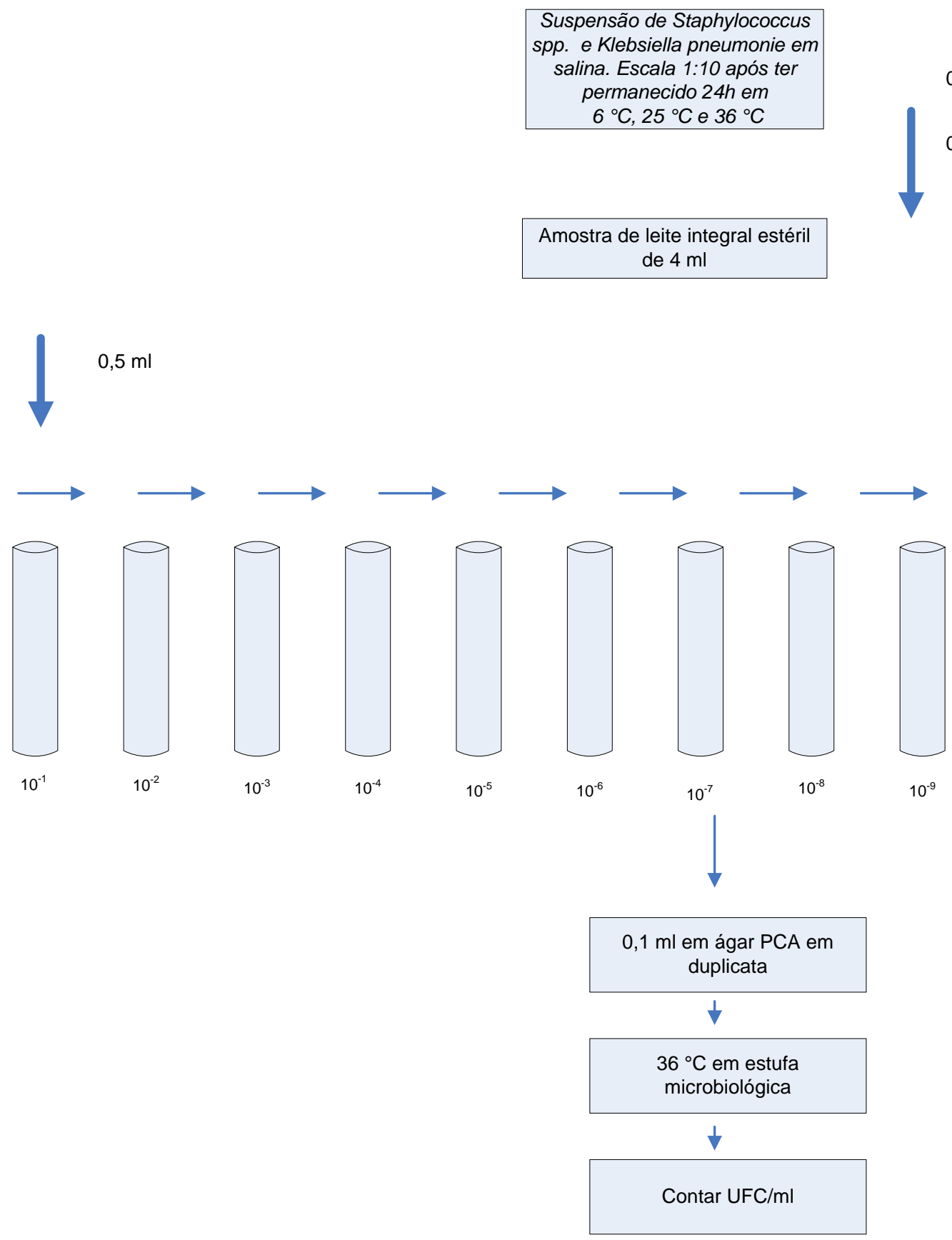

Figura 3 - Diluição da amostra de Staphylococcus spp. + Klebsiella pneumoniae até $10^{-9}$ e plaqueamento em duplicata 


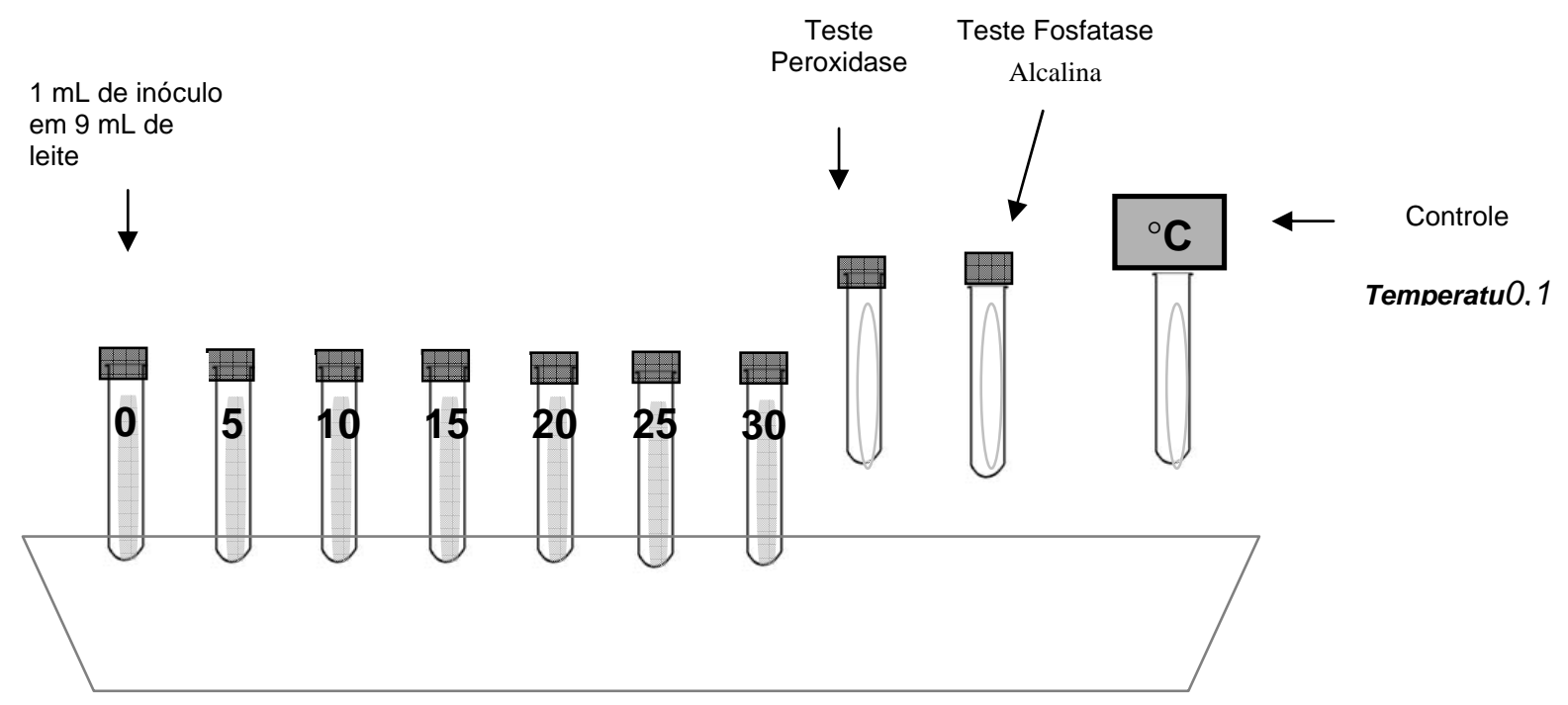

Banho-maria $85^{\circ} \mathrm{C}$
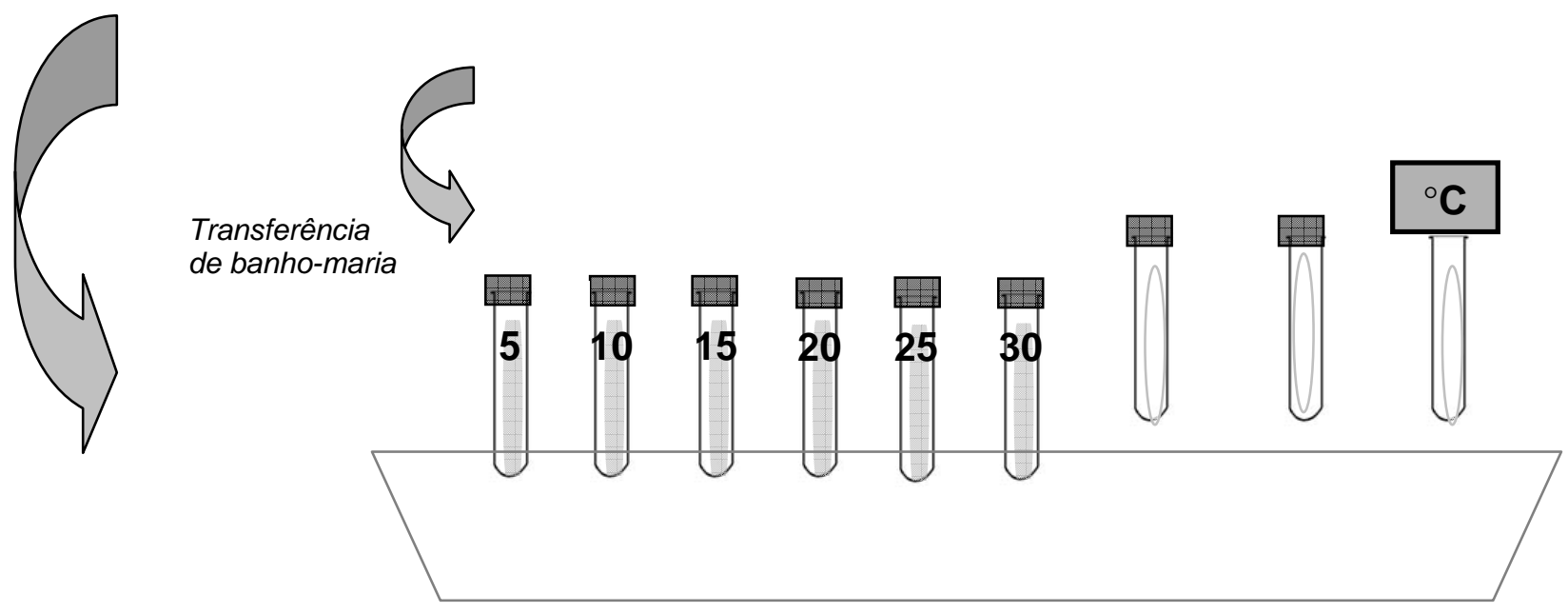

Banho-maria $65^{\circ} \mathrm{C}$

Figura 4 - Pasteurização, diluição e semeadura das sub-amostras 
Retirada da subamostra 0

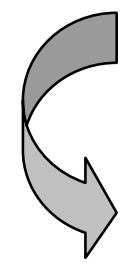

Diluição seriada da sub-amostra 0
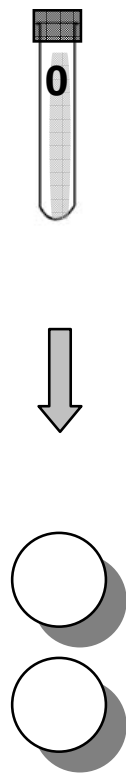

$0,1 \mathrm{~mL}$ da sub-amostra semeados em duplicata em meio PCA ou, também em MacConkey quando as bactérias estavam associadas

\section{$\begin{array}{llllll}5 & 10 & 15 & 20 & 25 & 30\end{array}$}
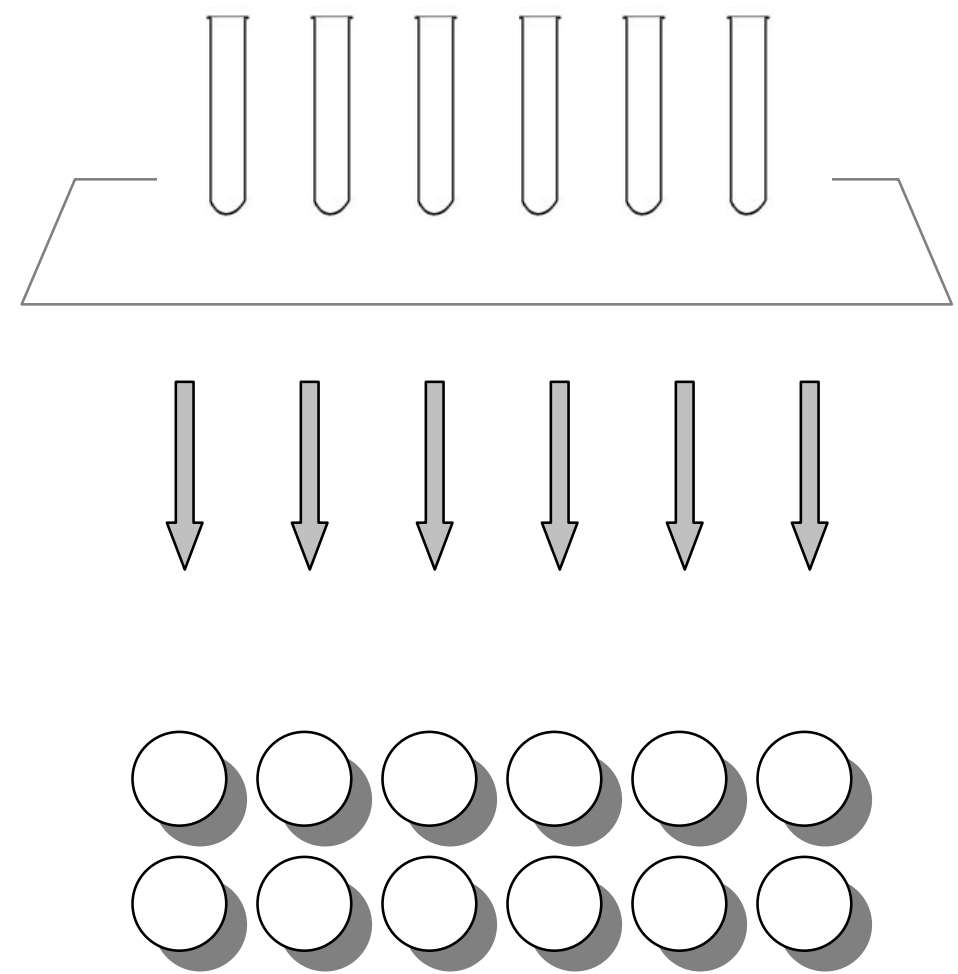

$0,1 \mathrm{~mL}$ de cada diluição, semeados em duplicata em meio PCA (PCA ou, também em MacConkey quando as bactérias estavam associadas) após cada "tempo" de pasteurização

Figura 5 - Pasteurização, diluição e semeadura das sub-amostras 
RESULTADOS 


\section{RESULTADOS}

$\mathrm{Na}$ tabela 1, descreve-se a média, mediana, valor mínimo e máximo encontrados na escala 1 de Mac Farland, utilizada para inocular Klebsiella pneumoniae e Staphylococcus spp. nas amostras de leite integral estéril para estudar o crescimento de unidades formadoras de colônias de Staphylococcus spp. e Klebsiella pneumoniae, isoladas de tanque de refrigeração de leite e o efeito da pasteurização lenta nestes microrganismos, em culturas puras e em associação.

A média de UFC/mL nas cepas de Klebsiella pneumoniae foi de 121,96, a mediana encontrada 107 e o valores mínimo e máximo foi 56 e 235, UFC/mL respectivamente (Tabela 1 ).

A média de UFC/mL para Staphylococcus spp. 79,288, com mediana de 66,25 e valores mínimo e máximo de 9,5 e 182,5 UFC/mL respectivamente (Tabela $1)$.

Tabela 1 - Média, mediana e valores mínimos e máximos do número de Unidades Formadoras de Colônias por mililitro da Escala 1 de Mac Farland - São Paulo - 2006/2007

Unidades Formadoras de Colônias

\begin{tabular}{lcccc}
\cline { 2 - 5 } Microrganismo & Média $^{1}$ & Mediana $^{2}$ & Mínimo $^{3}$ & Máximo $^{4}$ \\
\hline Klebsiella pneumonie & 121.96 & 107 & 56 & 235.5 \\
Staphylococcus spp. & 79.288 & 66.25 & 9.5 & 182.5 \\
\hline
\end{tabular}

\footnotetext{
1: Indica o valor da média da contagem de UFC

2: Indica o valor da mediana da contagem de UFC

3: Indica menor valor da contagem de UFC em pelo menos uma amostra

4: Indica maior valor da contagem de UFC em pelo menos uma amostra
} 
De acordo com os resultados da tabela 2 e com a aplicação do teste não paramétrico de Kruskal Wallis, há resultados estatisticamente significativos quando se analisa $K$. pneumoniae associada ao Staphylococcus spp. entre as temperaturas de $6^{\circ} \mathrm{C}$ e $25^{\circ} \mathrm{C}$ e entre $6^{\circ} \mathrm{C}$ e $36^{\circ} \mathrm{C}$, nestes valores há maior crescimento de $\mathrm{K}$. pneumoniae quanto maior a temperatura de incubação das colônias.

Quando se analisa Staphylococcus spp. associado a K. pneumoniae não é observado diferença no crescimento bacteriano nas três diferentes temperaturas (Tabela 2).

Quando se compara a interação entre as bactérias a $6^{\circ} \mathrm{C}$ não verificou nenhuma diferença estatisticamente significante entre o crescimento das linhagens, ou seja, houve crescimento igual de UFC entre as bactérias isoladas e em associação a $6^{\circ} \mathrm{C}$ (Tabela 2$)$.

A $25^{\circ} \mathrm{C}$ observou-se diferença estatisticamente significante entre 0 crescimento de (Tabela 2 ):

- Klebsiella pneumoniae isolada cresce mais que o Staphylococcus spp. isolado;

- Staphylococcus spp. isolado cresce mais que este associado a $K$. pneumoniae;

$\mathrm{Na}$ temperatura de $36{ }^{\circ} \mathrm{C}$ encontra-se diferença entre (Tabela 2):

- K. pneumoniae associada ao Staphylococcus spp. cresce mais e Staphylococcus spp. isolado;

- Staphylococcus spp. associado a K. pneumoniae cresce mais que Staphylococcus spp isolado.

Em todas as temperaturas a K. pneumoniae isolada ou em associação cresce mais que Staphylococcus spp isolado ou em associação (Tabela 2). 
Tabela 2 - Mediana e valores mínimo e máximo na contagem de Unidades Formadoras de Colônias de Klebsiella pneumoniae e Staphylococcus spp. isolados e em associação - São Paulo - 2006/2007

\begin{tabular}{|c|c|c|c|c|}
\hline Temperatura & $\begin{array}{l}\text { Microrganismos } \\
\text { e associações }\end{array}$ & Mediana & Mínimo & Máximo \\
\hline \multirow{4}{*}{$7^{\circ} \mathrm{C}$} & Klebsiella pneumoniae & 0.004575 & 0.001025 & 0.008575 \\
\hline & Staphylococcus spp & 0.003488 & 0 & 0.01280 \\
\hline & $\begin{array}{l}\text { K. pneumoniae associada } \\
\text { ao Staphylococcus spp. }\end{array}$ & 0.008113 & 0.0012 & 0.03393 \\
\hline & $\begin{array}{l}\text { Staphylococcus spp. associado } \\
\text { a K. pneumoniae }\end{array}$ & 0.001050 & 0 & 0.01395 \\
\hline \multirow{4}{*}{$25^{\circ} \mathrm{C}$} & Klebsiella pneumoniae & 46.5 & 4.5 & 64.5 \\
\hline & Staphylococcus spp & 6.625 & 0 & 16 \\
\hline & $\begin{array}{l}\text { K. pneumoniae associada } \\
\text { ao Staphylococcus spp. }\end{array}$ & 25 & 7.25 & 130 \\
\hline & $\begin{array}{l}\text { Staphylococcus spp. associado } \\
\text { a K. pneumoniae }\end{array}$ & 0 & 0 & 4 \\
\hline \multirow{4}{*}{$36^{\circ} \mathrm{C}$} & Klebsiella pneumoniae & 67 & 16.5 & 89 \\
\hline & Staphylococcus spp & 20.5 & 6 & 114.75 \\
\hline & $\begin{array}{l}\text { K. pneumoniae associada } \\
\text { ao Staphylococcus spp. }\end{array}$ & 35 & 7.5 & 163.5 \\
\hline & $\begin{array}{l}\text { Staphylococcus spp. associado } \\
\text { a K. pneumoniae }\end{array}$ & 0 & 0 & 18.75 \\
\hline
\end{tabular}


De acordo com os resultados da tabela 3, quando as linhagens de Klebsiella pneumoniae, semeadas em associação com cepas de Staphylococcus spp., desenvolvem-se em meio de cultura Mac Conkey, a mediana de crescimento foi de 0,00305 UFC/mL, mínimo de 0 UFC/mL e máximo de 0,01083 UFC/mL.

Quando as mesmas estirpes são semeadas em meio PCA, em associação com cepas de Staphylococcus spp., a mediana de crescimento foi de 0,008113 UFC/mL, mínimo de 0,0012 UFC/mL e máximo de 0,03393 UFC/mL. Entretanto quando as mesmas cepas são semeadas, isoladamente em meio de cultura PCA, a mediana de crescimento foi de 0,004575 UFC/mL, mínimo de 0,001025 UFC/mL e máximo de 0,008575 UFC/mL (Tabela 3).

A $6^{\circ} \mathrm{C}$ não há diferença entre o crescimento de UFC de $K$. pneumoniae isolada ou em associação com Staphylococcus spp., como pode ser visto na tabela 3 em ambos os meios utilizados $(p=0,209)$.

Tabela 3 - Crescimento de Unidades Formadoras de Colônias de cepas de Klebsiella pneumoniae isolada e em associação com Staphylococcus spp. em meio de cultura Mac Conkey e PCA na temperatura de crescimento de $6{ }^{\circ} \mathrm{C} / 24 \mathrm{~h}$ - São Paulo - 2006/2007

\begin{tabular}{lccc}
\hline \multicolumn{1}{c}{ Meio de Cultura } & Mediana $^{1}$ & Mínimo $^{2}$ & Máximo $^{3}$ \\
\hline Mac Conkey & 0.00305 & 0 & 0.01083 \\
PCA & 0.008113 & 0.0012 & 0.03393
\end{tabular}

(K. pneumoniae + Staphylococcus spp.)

\section{PCA isolada}

1: Indica o valor da mediana da contagem de UFC

0.004575

0.001025

0.008575

2: Indica o menor valor da contagem de UFC em pelo menos uma amostra

3: Indica o maior valor da contagem de UFC em pelo menos uma amostra 
$\mathrm{Na}$ temperatura de crescimento de $25{ }^{\circ} \mathrm{C}$ quando as cepas de Klebsiella pneumoniae, semeadas em associação com cepas de Staphylococcus spp., desenvolvem-se em meio de cultura Mac Conkey, a mediana de crescimento foi de 26,625 UFC/mL, mínimo de 10,25 UFC/mL e máximo de 91 UFC/mL (Tabela 4).

Quando as mesmas cepas são semeadas em meio PCA, em associação com cepas de Staphylococcus spp., a mediana de crescimento foi de 25 UFC/ mL, mínimo de 7,25 UFC/ mL e máximo de 130 UFC/ mL. Entretanto quando as mesmas cepas são semeadas, isoladamente em meio de cultura PCA, a mediana de crescimento foi de $46,5 \mathrm{UFC} / \mathrm{mL}$, mínimo de $4,5 \mathrm{UFC} / \mathrm{mL}$ e máximo de $64,5 \mathrm{UFC} / \mathrm{mL}$ (Tabela 4).

A $25^{\circ} \mathrm{C}$ não há diferença entre o crescimento de UFC de $K$. pneumoniae isolada ou em associação com Staphylococcus spp., como pode ser visto na tabela 4 , em ambos os meios utilizados $(p=0,64)$.

Tabela 4 - Crescimento de Unidades Formadoras de Colônias de cepas de Klebsiella pneumoniae isolada e em associação com Staphylococcus spp. em meio de cultura Mac Conkey e PCA na temperatura de crescimento de $25^{\circ} \mathrm{C} / 24 \mathrm{~h}$ - São Paulo - 2006/2007

\begin{tabular}{lccc}
\hline \multicolumn{1}{r}{ Meio de Cultura } & Mediana $^{1}$ & Mínimo $^{2}$ & Máximo $^{3}$ \\
\hline Mac Conkey & 26,625 & 10,25 & 91 \\
PCA & 25 & 7,25 & 130 \\
(K. pneumoniae + Staphylococcus spp.) & & & \\
PCA isolada & 46,5 & 4,5 & 64,5 \\
\hline
\end{tabular}

1: Indica o valor da mediana da contagem de UFC

2: Indica o menor valor da contagem de UFC em pelo menos uma amostra

3: Indica o maior valor da contagem de UFC em pelo menos uma amostra 
Quando os microrganismos ficaram expostos à temperatura de crescimento de $36^{\circ} \mathrm{C}$, as cepas de Klebsiella pneumoniae semeadas em associação com cepas de Staphylococcus spp., em meio de cultura Mac Conkey, a mediana de crescimento foi de 20,25 UFC/mL, mínimo de 5,5 UFC/mL e máximo de 123,75 UFC/mL (Tabela 5).

Quando as mesmas cepas foram semeadas em meio PCA, em associação com cepas de Staphylococcus spp., a mediana de crescimento foi de $35 \mathrm{UFC} / \mathrm{mL}$, mínimo de 7,5 UFC/mL e máximo de 163,5 UFC/mL (Tabela 5).

Entretanto quando as mesmas cepas são semeadas, isoladamente em meio de cultura PCA, a mediana de crescimento foi de $67 \mathrm{UFC} / \mathrm{mL}$, mínimo de 16,5 UFC/mL e máximo de $89 \mathrm{UFC} / \mathrm{mL}$ (Tabela 5 ).

Quando se comparou o crescimento das cepas de Klebsiella pneumoniae no meio de cultura PCA semeadas isoladamente e em associação com cepas de Staphylococcus spp., como pode ser observado na tabela 5, o valor de $p$ foi de 0,0109 considerado estatisticamente significante, ou seja, a $36{ }^{\circ} \mathrm{C}$, no meio de cultura PCA, a K. pneumoniae isolada cresce mais que a mesma cepa semeada em meio de cultura Mac Conkey.

Tabela 5 - Crescimento de Unidades Formadoras de Colônias de cepas de Klebsiella pneumoniae isolada e em associação com Staphylococcus spp. em meio de cultura Mac Conkey e PCA na temperatura de crescimento de $36{ }^{\circ} \mathrm{C} / 24 \mathrm{hn}$ - São Paulo - 2006/2007

\begin{tabular}{lccc}
\hline \multicolumn{1}{c}{ Meio de Cultura } & Mediana $^{1}$ & Mínimo $^{2}$ & Máximo $^{3}$ \\
\hline Mac Conkey & 20,25 & 5,5 & 123,75 \\
PCA & & & \\
(K. pneumoniae + Staphylococcus spp.) & 35 & 7,5 & 163,5 \\
PCA isolada & 67 & 16,5 & 89 \\
\hline 1: Indica o valor da mediana da contagem de UFC & & \\
2: Indica o menor valor da contagem de UFC em pelo menos uma amostra & & \\
3: Indica o maior valor da contagem de UFC em pelo menos uma amostra &
\end{tabular}




\subsection{RESULTADOS DA PASTEURIZAÇÃO LENTA}

Na tabela 6, está descrito o tempo de pasteurização de 0 (zero) a 30 minutos (intervalo a cada 5 minutos), com as respectivas médias de cada tempo de pasteurização, mediana, mínimo e máximo.

No início do processo de pasteurização (0 Minuto), a média, mediana, mínimo e máximo encontrados de foram de $250 \mathrm{UFC} / \mathrm{mL}$, com desvio padrão igual a zero; após 5 minutos de pasteurização a média foi de 10,43 UFC/mL com desvio padrão de 14,58, mediana 5, mínimo 1 e máximo $41 \mathrm{UFC} / \mathrm{mL}$; após 10 minutos de pasteurização a média foi de 2,86 UFC/mL com desvio padrão de 4,22, mediana 1 , mínimo 0 e máximo $12 \mathrm{UFC/mL;} \mathrm{após} 15$ minutos de pasteurização a média foi de 2,7 UFC/mL com desvio padrão de 5,53, mediana e mínimo 0 e máximo 15 UFC/mL; após 20 minutos de pasteurização a média foi de $1,14 \mathrm{UFC} / \mathrm{mL}$ com desvio padrão de 3,02, mediana e mínimo 0 e máximo $8 \mathrm{UFC} / \mathrm{mL}$; após 25 minutos de pasteurização a média, desvio padrão, mediana, mínimo, e máximo foi de 0 $\mathrm{UFC} / \mathrm{mL}$; após $\mathbf{3 0}$ minutos de pasteurização a média foi de 0,14 UFC/mL com desvio padrão de 0,19, mediana e mínimo 0 e máximo 1 UFC/mL (Tabela 6). 
Tabela 6 - Média, mediana e valores mínimo e máximo do processo de pasteurização lenta, demonstrando a curva de morte térmica a cada cinco minutos ( 0 a 30 minutos), para Klebsiella pneumoniae isolada São Paulo - 2006/2007

\begin{tabular}{ccccc}
\multicolumn{5}{c}{ Pasteurização lenta - K. Pneumoniae IS OLADA - Tempo (min) /UFC } \\
\hline Tempo (minuto) & Média/ (DP) & Mediana $^{2}$ & Mínimo $^{3}$ & Máximo $^{4}$ \\
\hline 0 (zero) & $\begin{array}{c}250 \\
( \pm 0)\end{array}$ & 250 & 250 & 250 \\
5 & $\begin{array}{c}10,43 \\
( \pm 14,58) \\
2,86 \\
( \pm 4,22)\end{array}$ & 5 & 1 & 41 \\
10 & $\begin{array}{c}2,7 \\
\pm 5,53) \\
1,14 \\
15\end{array}$ & 0 & 0 & 12 \\
20 & $\begin{array}{c} \pm 3,02) \\
0\end{array}$ & 0 & 0 & 15 \\
25 & $\begin{array}{c}( \pm 0) \\
0,14\end{array}$ & 0 & 0 & 0 \\
30 & $( \pm 0,19)$ & & 0 & 1
\end{tabular}

$* \mathrm{DP}= \pm$ Desvio Padrão

1: Indica o valor da media da contagem de UFC

2: Indica o valor da mediana da contagem de UFC

3: Indica menor valor da contagem de UFC em pelo menos uma amostra

4: Indica maior valor da contagem de UFC em pelo menos uma amostra 
Na tabela 7 , está descrito o tempo de pasteurização de 0 (zero) a 30 minutos (intervalo a cada 5 minutos), com as respectivas médias de cada tempo de pasteurização, mediana, mínimo e máximo.

No início do processo de pasteurização (0 Minuto), a média, mediana, mínimo e máximo encontrados de foi de $250 \mathrm{UFC} / \mathrm{mL}$, com desvio padrão igual a zero; após 5 minutos de pasteurização a média foi de $64,2 \mathrm{UFC} / \mathrm{mL}$ com desvio padrão de 100,66, mediana 15,5, mínimo 1 e máximo $250 \mathrm{UFC} / \mathrm{mL}$; após 10 minutos de pasteurização a média foi de 8,2 UFC/mL com desvio padrão de 11,03, mediana 5, mínimo 0 e máximo $37 \mathrm{UFC} / \mathrm{mL}$; após 15 minutos de pasteurização a média foi de 36,2 UFC/mL com desvio padrão de 77,65, mediana 1,5, mínimo 0 e máximo 250 UFC/mL; após 20 minutos de pasteurização a média foi de $26 \mathrm{UFC/mL} \mathrm{com} \mathrm{desvio}$ padrão de 44,42, mediana 1,5, mínimo 0 e máximo 139 UFC/mL; após 25 minutos de pasteurização a média foi de $9,8 \mathrm{UFC} / \mathrm{mL}$, desvio padrão de 22,41, mediana 1,5, mínimo 0, e máximo de $73 \mathrm{UFC/mL}$; após 30 minutos de pasteurização a média foi de 7,2 UFC/mL com desvio padrão de 6,78, mediana 4, mínimo 0 e máximo 21 UFC/mL (Tabela 7). 
Tabela 7 - Resultados da média, mediana e valores mínimo e máximo do processo de pasteurização lenta, demonstrando a curva de morte térmica a cada cinco minutos (0 a 30 minutos), para Staphylococcus spp.isolado - São Paulo - 2006/2007

Pasteurização lenta - Staphylococcus spp. ISOLADO

\begin{tabular}{ccccc}
\hline Tempo (minuto) & Média/ $(\mathrm{DP})^{1}$ & Mediana $^{2}$ & Mínimo $^{3}$ & Máximo $^{4}$ \\
\hline 0 (zero) & $\begin{array}{c}250 \\
( \pm 0)\end{array}$ & 250 & 250 & 250 \\
5 & $\begin{array}{l}64,2 \\
( \pm 100,66)\end{array}$ & 15,5 & 1 & 250 \\
10 & $\begin{array}{c}8,2 \\
( \pm 11,03) \\
36,2\end{array}$ & 5 & 0 & 37 \\
15 & $( \pm 77,65)$ & 1,5 & 0 & 250 \\
20 & $\begin{array}{c}26 \\
( \pm 44,42) \\
9,8\end{array}$ & 1,5 & 0 & 139 \\
25 & $( \pm 22,41)$ & 1,5 & 0 & 73 \\
70 & $( \pm, 2$ & 4 & 0 & 21 \\
& & & & \\
\hline
\end{tabular}

$* \mathrm{DP}= \pm$ Desvio Padrão

1: Indica o valor da media da contagem de UFC

2: Indica o valor da mediana da contagem de UFC

3: Indica menor valor da contagem de UFC em pelo menos uma amostra

4: Indica maior valor da contagem de UFC em pelo menos uma amostra 
Está representada no gráfico 1, a curva de morte térmica durante o processo de pasteurização lenta quando as cepas de Staphylococcus spp. e Klebsiella pneumoniae foram pasteurizadas isoladamente .

A curva azul demonstra o processo nas cepas de Staphylococcus spp., no início do processo (0 minuto) há $250 \mathrm{UFC} / \mathrm{mL}$, após 5 minutos de pasteurização a $65^{\circ} \mathrm{C}$ o número de UFC/mL passa para 64,2 , após 10 minutos para 8,2 , após 15 minutos para 36,2, após 20 minutos para 26, após 25 minutos para 9,8 e após $\mathbf{3 0}$ minutos de pasteurização foram contadas 7,2 UFC/mL (Gráfico 1).

A curva rosa demonstra o processo nas cepas de Klebsiella pneumoniae, no início do processo (0 minuto) há $250 \mathrm{UFC/} \mathrm{mL}$, após 5 minutos de pasteurização a $65^{\circ} \mathrm{C}$ o número de UFC/mL passa para 10,43 , após 10 minutos para 2,86, após 15 minutos para 2,7, após 20 minutos para 1,14, após 25 minutos para 0 e após 30 minutos de pasteurização foram contadas 0,14 UFC/mL (Gráfico 1). 


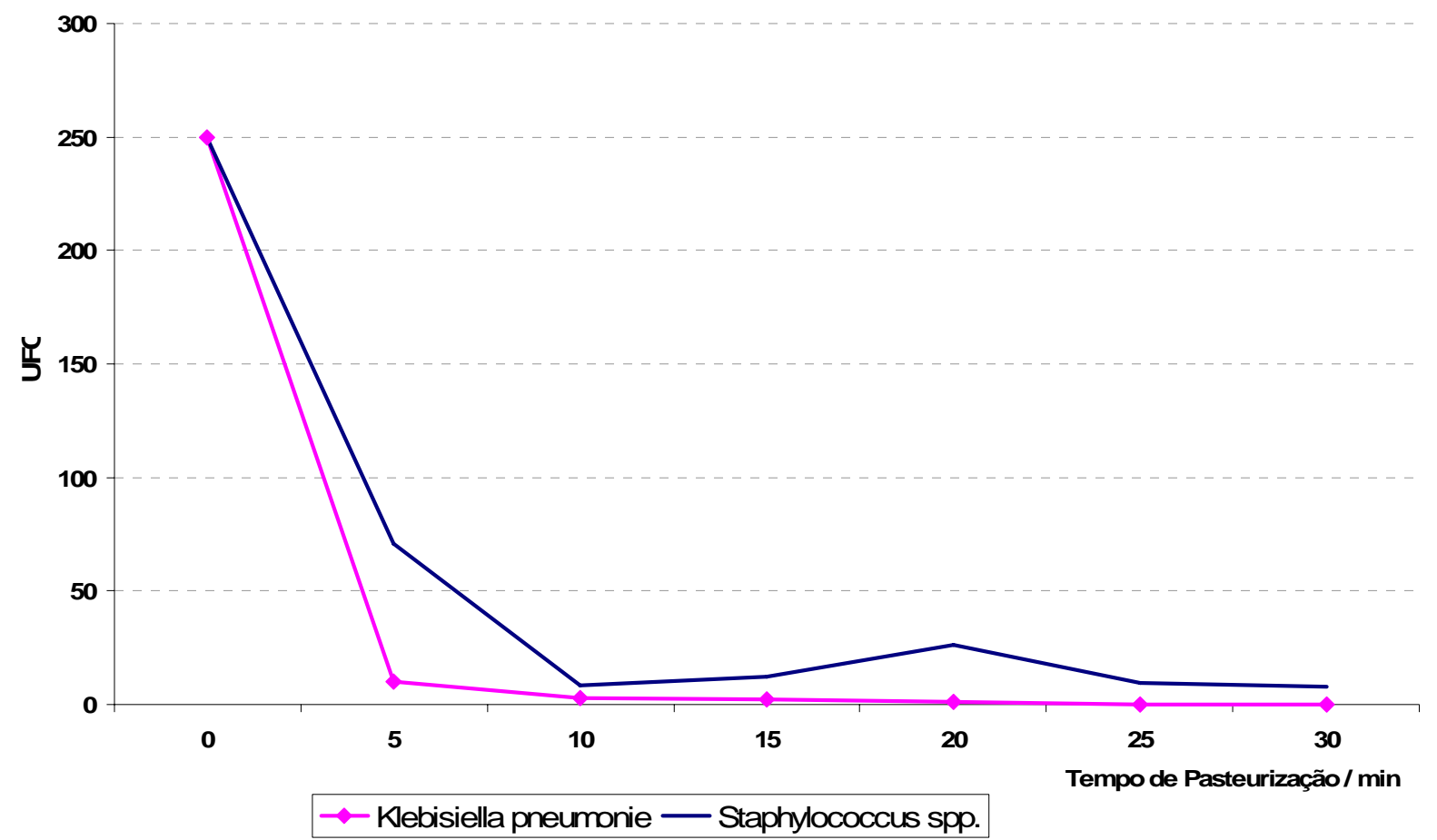

Gráfico 1 - Curva de Morte térmica da média de Unidades Formadoras de Colônia (UFC), durante o processo de pasteurização lenta para Klebsiella pneumoniae e Staphylococcus spp. pasteurizados isoladamente 
$\mathrm{Na}$ tabela 8, está descrito o tempo de pasteurização de 0 (zero) a 30 minutos (intervalo a cada 5 minutos), com as respectivas médias de cada tempo de pasteurização, mediana, mínimo e máximo.

No início do processo de pasteurização (0 Minuto), a média, mediana, mínimo e máximo encontrados de foi de $250 \mathrm{UFC} / \mathrm{mL}$, com desvio padrão igual a zero; após 5 minutos de pasteurização a média foi de 37,3 UFC/mL com desvio padrão de 24,37, mediana 35, mínimo 3 e máximo $80 \mathrm{UFC} / \mathrm{mL}$; após 10 minutos de pasteurização a média foi de $62,4 \mathrm{UFC} / \mathrm{mL}$ com desvio padrão de 72 , mediana 46,5 , mínimo 3 e máximo $250 \mathrm{UFC/mL;} \mathrm{após} 15$ minutos de pasteurização a média foi de $112,8 \mathrm{UFC} / \mathrm{mL}$ com desvio padrão de 89,33, mediana 76, mínimo 28 e máximo 250 UFC/mL; após 20 minutos de pasteurização a média foi de 110,8 UFC/mL com desvio padrão de 83,06, mediana 127,5, mínimo 2 e máximo $250 \mathrm{UFC/mL;} \mathrm{após} 25$ minutos de pasteurização a média de $51,1 \mathrm{UFC} / \mathrm{mL}$, desvio padrão de 60,2 , mediana 15,5, mínimo 3 e máximo de $150 \mathrm{UFC} / \mathrm{mL}$; após 30 minutos de pasteurização a média foi de $91 \mathrm{UFC} / \mathrm{mL}$ com desvio padrão de 105,12, mediana 27,5, mínimo 3 e máximo 250 UFC/mL (Tabela 8). 
Tabela 8 - Resultados da média, mediana e valores mínimo e máximo do processo de pasteurização lenta, demonstrando a curva de morte térmica a cada cinco minutos (0 a 30 minutos), para Klebsiella pneumoniae associada à Staphylococcus spp. - São Paulo - 2006/2007

Pasteurização lenta - Klebsiella pneumoniae associada à Staphylococcus spp.

\begin{tabular}{ccccc}
\hline Tempo (minuto) & ${\text { Média/ (DP })^{1}}^{1}$ & Mediana $^{2}$ & Mínimo $^{3}$ & Máximo $^{4}$ \\
\hline 0 (zero) & 250 & 250 & 250 & 250 \\
5 & $\begin{array}{c}( \pm 0) \\
37.3\end{array}$ & 35 & 3 & 80 \\
10 & $\begin{array}{c} \pm 24,37) \\
62.4\end{array}$ & 46.5 & 3 & 250 \\
15 & $\begin{array}{c}( \pm 72) \\
112.8\end{array}$ & 76 & 28 & 250 \\
20 & $\begin{array}{c}( \pm 89.33) \\
110.8 \\
( \pm 83.06)\end{array}$ & 127.5 & 2 & 250 \\
25 & $\begin{array}{c}51,1 \\
( \pm 60.2)\end{array}$ & 15,5 & 3 & 150 \\
30 & 91 & 27.5 & 3 & 250 \\
& $( \pm 105.12)$ & & & \\
\hline
\end{tabular}

$* \mathrm{DP}= \pm$ Desvio Padrão

1: Indica o valor da media da contagem de UFC

2: Indica o valor da mediana da contagem de UFC

3: Indica menor valor da contagem de UFC em pelo menos uma amostra

4: Indica maior valor da contagem de UFC em pelo menos uma amostra 
$\mathrm{Na}$ tabela 9, está descrito o tempo de pasteurização de 0 (zero) a 30 minutos (intervalo a cada 5 minutos), com as respectivas médias de cada tempo de pasteurização, mediana, mínimo e máximo.

No início do processo de pasteurização (0 Minuto), a média, mediana, mínimo e máximo encontrados de foi de $250 \mathrm{UFC} / \mathrm{mL}$, com desvio padrão igual a zero; após 5 minutos de pasteurização a média foi de 123,78 UFC/mL com desvio padrão de 105,22, mediana 100, mínimo 1 e máximo $250 \mathrm{UFC/mL;} \mathrm{após} 10$ minutos de pasteurização a média foi de 94,22 UFC/mL com desvio padrão de 99,93, mediana 50, mínimo 2 e máximo $250 \mathrm{UFC} / \mathrm{mL}$; após 15 minutos de pasteurização a média foi de 78,56 UFC/mL com desvio padrão de 83,45, mediana 60, mínimo $1 \mathrm{e}$ máximo $250 \mathrm{UFC} / \mathrm{mL}$; após 20 minutos de pasteurização a média foi de 73,11 UFC/mL com desvio padrão de 81,16, mediana 38, mínimo 1 e máximo 250 UFC/mL; após 25 minutos de pasteurização a média de $62,11 \mathrm{UFC} / \mathrm{mL}$, desvio padrão de 61,87, mediana 30, mínimo 10 e máximo de $175 \mathrm{UFC} / \mathrm{mL}$; após 30 minutos de pasteurização a média foi de $105,44 \mathrm{UFC} / \mathrm{mL}$ com desvio padrão de 98,41, mediana 102, mínimo 1 e máximo 250 UFC/mL (Tabela 9). 
Tabela 9 - Resultados da média, mediana e valores mínimo e máximo do processo de pasteurização lenta, demonstrando a curva de morte térmica a cada cinco minutos (0 a 30 minutos), para Staphylococcus spp. associado à Klebsiella pneumoniae - São Paulo - 2006/2007

Pasteurização lenta - Staphylococcus spp. associado à Klebsiella pneumoniae

\begin{tabular}{ccccc}
\hline Tempo (minuto) & ${\text { Média/ (DP })^{1}}^{2}$ & Mediana $^{2}$ & Mínimo $^{3}$ & Máximo $^{4}$ \\
\hline 0 (zero) & $\begin{array}{c}250 \\
( \pm 0)\end{array}$ & 250 & 250 & 250 \\
5 & $\begin{array}{c}123,78 \\
( \pm 105,22)\end{array}$ & 100 & 1 & 250 \\
10 & $\begin{array}{c}94,22 \\
( \pm 99,93) \\
78,56\end{array}$ & 50 & 2 & 250 \\
15 & $\begin{array}{c}( \pm 83,45) \\
73,11\end{array}$ & 30 & 1 & 250 \\
20 & $\begin{array}{c}( \pm 81,16) \\
62,11 \\
( \pm 61,87) \\
105,44 \\
( \pm 98.41)\end{array}$ & 30 & 10 & 250 \\
30 & & 102 & 1 & 250 \\
\hline
\end{tabular}

* DP $= \pm$ Desvio Padrão

1: Indica o valor da media da contagem de UFC

2: Indica o valor da mediana da contagem de UFC

3: Indica menor valor da contagem de UFC em pelo menos uma amostra

4: Indica maior valor da contagem de UFC em pelo menos uma amostra 
Está representada no gráfico 2, a curva de morte térmica durante o processo de pasteurização lenta quando as cepas de Staphylococcus spp. e Klebsiella pneumoniae foram pasteurizadas em associação .

A curva azul demonstra o processo nas cepas de Staphylococcus spp., no início do processo (0 minuto) há $250 \mathrm{UFC} / \mathrm{mL}$, após $\mathbf{5}$ minutos de pasteurização a $65{ }^{\circ} \mathrm{C}$ o número de UFC/mL passa para 123,78 , após 10 minutos para 94,22 , após 15 minutos para 78,56, após 20 minutos para 73,11, após 25 minutos para 62,11 e após 30 minutos de pasteurização foram contadas 105,44 UFC/mL (Gráfico 2).

A curva rosa demonstra o processo nas cepas de Klebsiella pneumoniae, no início do processo (0 minuto) há $250 \mathrm{UFC} / \mathrm{mL}$, após 5 minutos de pasteurização a $65{ }^{\circ} \mathrm{C}$ o número de UFC/mL passa para 37,3 , após 10 minutos para 62,4 , após 15 minutos para 112,8, após 20 minutos para 110,8, após 25 minutos para 51,1 e após 30 minutos de pasteurização foram contadas $91 \mathrm{UFC/mL}$ (Gráfico 2). 


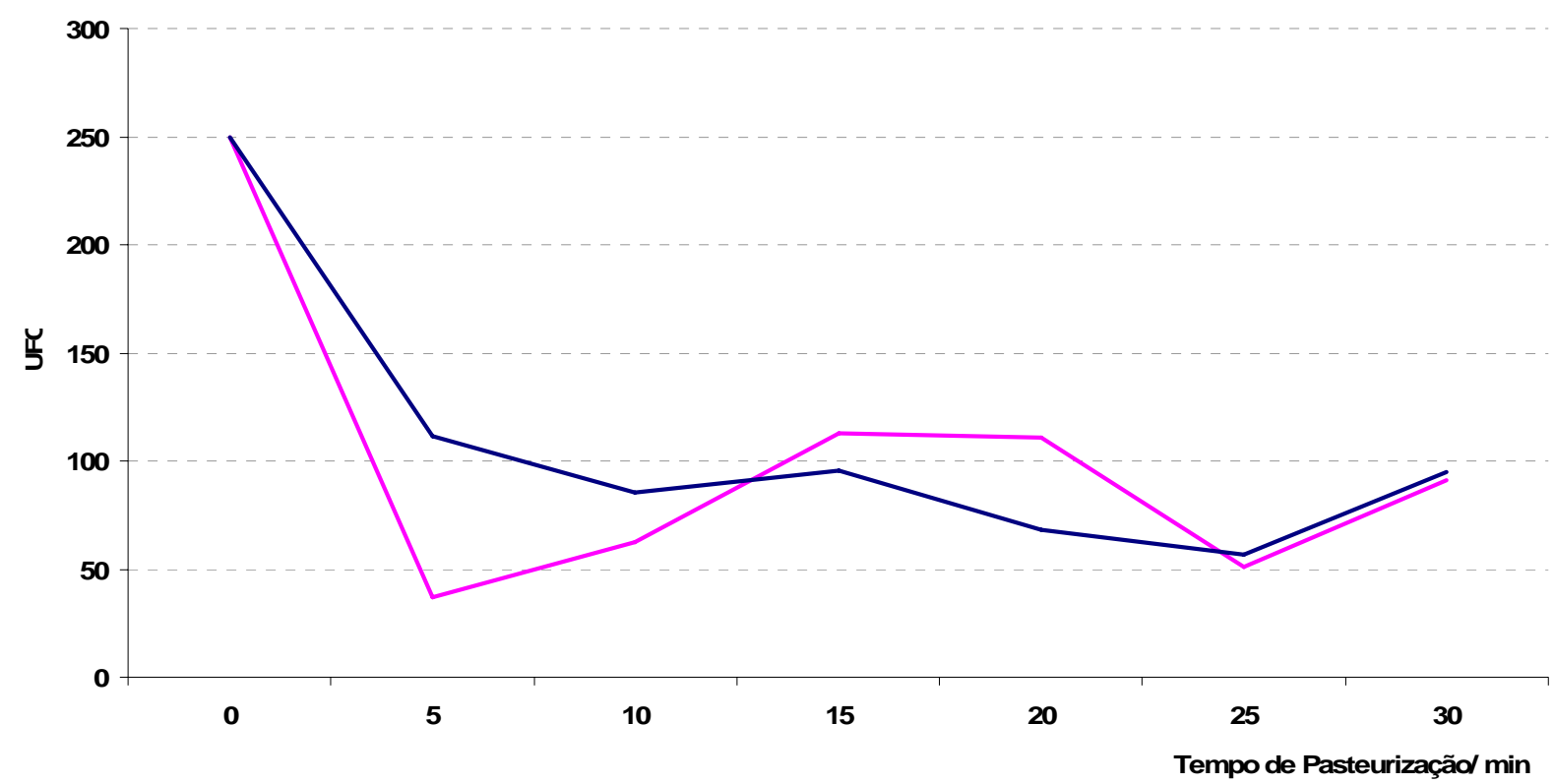

Klebisiella pneumonie — Staphylococcus spp.

Gráfico 2 - Curva de Morte térmica da média de Unidades Formadoras de Colônia (UFC) durante o processo de pasteurização lenta para Klebsiella pneumoniae e Staphylococcus spp. pasteurizados em associação 
Quando se analisa se há diferença estatística na pasteurização lenta com a Klebsiella pneumoniae isolada comparado à pasteurização lenta da Klebsiella pneumoniae associada ao Staphylococcus spp. encontra-se que há diferença estatisticamente significante através do teste de Kruskal-Wallis e o respectivo valor de "p" em todas as etapas do processo (Tabela 10), ou seja há maior eliminação de microrganismos quando esses são pasteurizados isoladamente.

Entre a pasteurização isolada de Staphylococcus spp. e associada entre Staphylococcus spp. e Klebsiella pneumoniae apenas não se encontra resultados estatisticamente significante através do teste Kruskal-Wallis no tempo de 15 e 20 minutos, ou seja, no tempo, 5, 10, 25 e 30 minutos há maior eliminação de microrganismos quando esses são pasteurizados isoladamente (Tabela 10).

Tabela 10 - Comparação entre 0 processo de pasteurização quando os microrganismos são submetidos ao processo isoladamente e em associação através do teste não paramétrico de Kruskal-Wallis - São Paulo - 2006/2007

\begin{tabular}{lrr}
\hline \multirow{2}{*}{ Tempo (min) } & $\begin{array}{c}\text { K. pneumoniae } \\
\text { isolada X associada }\end{array}$ & $\begin{array}{r}\text { Staphylococcus spp. } \\
\text { isolado X associado }\end{array}$ \\
\cline { 2 - 3 } valor de $\mathbf{p}$ & valor de $\mathbf{p}$ \\
\hline 5 & $0,01^{*}$ & 0,17 \\
10 & $0,001^{*}$ & $0,01^{*}$ \\
15 & $0,0006^{*}$ & 0,06 \\
20 & $0,0007^{*}$ & 0,05 \\
25 & $0,0004^{*}$ & $0,001^{*}$ \\
30 & $0,03^{*}$ & $0,01^{*}$ \\
\hline * Resultados estatísticamente significantes &
\end{tabular}


De acordo com a tabela 11, a função mais adequada aos valores obtidos com o processo de pasteurização é a função cúbica, onde se observa que:

- 92,24 \% dos valores são enquadrados na função cúbica quando a Klebsiella pneumoniae é pasteurizada isoladamente;

- 77,6 \% dos valores são enquadrados na função cúbica quando a Staphylococcus spp. é pasteurizado isoladamente;

- 32,6 \% dos valores são enquadrados na função cúbica quando a Klebsiella pneumoniae é pasteurizada em associação ao Staphylococcus spp.

- $32,8 \%$ dos valores são enquadrados na função cúbica quando o Staphylococcus spp. é pasteurizado em associação a Klebsiella pneumoniae. 
Tabela 11 - Representação da função que mais se adequou à distribuição espacial dos resultados no processo de pasteurização lenta para Klebsiella pneumoniae e Staphylococcus spp, isolados e em associação - São Paulo - 2006/2007

\section{Microrganismos}

e associações

Modelo

Rsq

d.f Sigf

b0

b1

b2

b3

$\begin{array}{lcccccccc} & \text { Linear } & 0,403 & 47 & 0 & 120,712 & -5,5107 & \\ \begin{array}{l}\text { Klebsiella pneumoniae } \\ \text { Isolada }\end{array} & \text { Quadrático } & 0,745 & 46 & 0 & 193,879 & -23,071 & 0,5853 & \\ & \text { Cúbico } & \mathbf{0 , 9 2 4} & \mathbf{4 5} & \mathbf{0 . 0 0 0} & \mathbf{2 3 3 , 5 9 4} & \mathbf{- 4 9 , 5 4 7} & \mathbf{2 , 9 6 8 2} & \mathbf{- 0 , 5 3} \\ & & & & & & & & \\ & & & & & & & & \\ & & & & & & & & \\ \text { Staphylococcus spp. } & \text { Qunear } & 0,411 & 61 & 0 & 144,03 & -5,9385 & & \\ \text { Isolado } & \text { Quadrático } & 0,666 & 60 & 0 & 211,665 & -22,171 & 0,5411 & \\ & \text { Cúbico } & \mathbf{0 , 7 7 6} & \mathbf{5 9} & \mathbf{0 . 0 0 0} & \mathbf{2 4 4 , 8 5 1} & \mathbf{- 4 4 , 2 9 4} & \mathbf{2 , 5 3 2} & \mathbf{- 0 , 4 4}\end{array}$

$\begin{array}{lcccccccc}\text { Klebsiella pneumoniae } & \text { Linear } & 0,092 & 68 & 0,011 & 145,05 & -2,867 & & \\ \text { associada ao } & \text { Quadrático } & 0,195 & 67 & 0,001 & 188,818 & -13,371 & 0,3501 & \\ \text { Staphylococcus spp. } & \text { Cúbico } & \mathbf{0 , 3 2 6} & \mathbf{6 6} & \mathbf{0 . 0 0 0} & \mathbf{2 2 5 , 7 1 8} & \mathbf{- 3 7 , 9 7 1} & \mathbf{2 , 5 6 4} & \mathbf{- 0 , 0 5}\end{array}$

\begin{tabular}{lcccccccc} 
Staphylococcus spp. & Linear & 0,179 & 68 & 0,011 & 172,343 & $-4,231$ & \\
associado à & Quadrático & 0,312 & 67 & 0.000 & 224,819 & $-16,826$ & 0,4198 \\
Klebsiella pneumoniae & Cúbico & $\mathbf{0 , 3 2 8}$ & $\mathbf{6 6}$ & $\mathbf{0 . 0 0 0}$ & $\mathbf{2 3 8 , 6 6 1}$ & $\mathbf{- 2 6 , 0 5 3}$ & $\mathbf{1 , 2 5}$ & $\mathbf{- 0 , 0 1 8 5}$ \\
\hline
\end{tabular}

Rsq: qualidade do ajuste da função

d.f: grau de liberdade

Sigf: Significância $(P<0,05)$

b0, b1,b2,b3: parâmetros das equações 


\section{DISCUSSÃO}




\section{DISCUSSÃO}

Nos últimos anos, ênfase crescente vem sendo dada à segurança alimentar, principalmente visando assegurar a melhor proteção do consumidor e possibilitando que fundamentos científicos sejam utilizados no estabelecimento de padrões, especificações e recomendações aplicadas ao controle de alimentos (BARBOSA; JORGE; UENO et al., 2007), uma vez que a presença de microrganismos patogênicos, aliada às práticas inadequadas de processamento, armazenamento e falta de higiene, podem provocar intoxicações alimentares, constituindo potencial risco à Saúde Pública (SOUZA et al., 2005).

A estreita relação entre o consumo de leite e seus derivados e a melhoria da qualidade de vida é sistematicamente defendida por pesquisadores de todo 0 mundo. Os derivados do leite são apreciados tanto pelo seu valor nutritivo como pelo seu sabor, que atendem aos mais exigentes paladares. No entanto, as condições de obtenção da matéria prima, do processamento e armazenamento, podem comprometer suas características organolépticas, bem como torná-las impróprias para o consumo, em virtude da contaminação por microrganismos responsáveis por toxinfecções alimentares (FREO; REOLON, 2006).

Como os Estafilococos são os microrganismos que causam, com maior freqüência, mastites em vacas leiteiras e as Klebsiellas são encontradas no leite devido à falta de higiene durante o processo de obtenção e manipulação da matéria prima, foi estudada nesse trabalho a interação, entre as estirpes de Staphylococcus spp. e Klebsiella pneumoniae, isolados de leite mastíticos e de tanque de refrigeração, em cultura pura e associação, em temperaturas que reproduzem a possível conservação desse alimento, e, o efeito da pasteurização lenta nos mesmos microrganismos, a fim de conhecer a interação destas linhagens, após 0 tratamento térmico, e com isso, a qualidade do produto final ao qual o consumidor está tendo acesso. Entretanto, há a necessidade de mais pesquisas semelhantes para avaliar a interação entre diferentes tipos de microrganismos, pois, não foi verificado na literatura, trabalhos semelhantes a este. 
Na avaliação da média de UFC da Escala 1 de Mac Farland, em ágar PCA, utilizadas para realização deste trabalho, observou-se maior número de UFC de Klebsiella pneumoniae, quando comparada à de Staphylococcus spp.; como, em ambas as culturas, a turvação na escala 1 de Mac Farland foi rigorosamente respeitada, acredita-se que esta diferença deva-se às características estruturais de cada gênero, tais como tamanho, cor e densidade.

Quando se comparou o crescimento bacteriano entre os dois meios de culturas, PCA e Mac Conckey, não foi encontrado diferença no crescimento bacteriano nas estirpes estudadas, após 24 horas nas temperaturas de 6 e $25{ }^{\circ} \mathrm{C}$, mostrando que os dois meios podem ser utilizados como padrão para contagem de UFC em placas, nestas condições. Entretanto, a $36{ }^{\circ} \mathrm{C}$, houve maior crescimento de UFC no meio de cultura PCA, demonstrando que caso seja utilizado o meio de cultura Mac Conkey, pode ocorrer uma subestimação do número real de UFC em leite.

O gênero Staphylococcus é formado, atualmente, por 32 espécies, destas 0 Staphylococcus aureus é a mais relacionada a casos e a surtos de intoxicação alimentar, devido à capacidade da maioria de suas cepas de produzir enterotoxinas. $\mathrm{Na}$ literatura é descrito inúmeros surtos de intoxicação alimentar causada pela ingestão de alimentos contendo enterotoxinas estafilocócicas pré-formadas. Em função do risco à saúde pública que sua presença representa em alimentos, estabeleceu-se, em diversos países, a obrigatoriedade de sua pesquisa e enumeração, como parte das ações de fiscalização sanitária de órgãos governamentais (SILVA; GANDRA, 2004).

Além de intoxicações alimentares, os Estafilococos são os agentes mais comuns de infecções piogênicas, tais como: foliculite, furunculose, carbúnculo e impetigo. Em indivíduos debilitados, podem provocar infecções de caráter mais grave como osteomielite, bacteremia, endocardite, pneumonia, meningite e artrite bacteriana. Além de infecções piogênicas, os estafilococos podem causar vários tipos de intoxicações, tais como a Síndrome da pele escaldada e a síndrome do choque tóxico (MARTINS, 1999).

Em relação a alimentos, o grupo dos estafilococos coagulase positiva (capazes de produzir a enzima coagulase) são os mais importantes, porque sua presença nesses produtos, pode indicar deficiência de processamento ou condições 
higiênicas inadequadas do processo, e que suas enterotoxinas, uma vez presente no alimento, poderão causar intoxicação alimentar mesmo que o alimento tenha passado pelo tratamento térmico como a pasteurização e a ultra-pasteurização, devido a sua termoestabilidade (SILVA; GANDRA, 2004).

Neste trabalho, a maior quantidade de Staphylococcus spp. foi encontrada quando o leite permaneceu, por 24 horas, armazenado em temperatura de refrigeração $\left(6^{\circ} \mathrm{C}\right)$. Como este microrganismo é frequentemente isolado de glândulas mamarias mastísticas, o cuidado na prevenção à infecção deve ser intensificado para evitar que o consumidor adquira leite contaminado com Staphylococcus spp. e possa desenvolver qualquer um dos problemas descritos, uma vez que esse microrganismo é capaz de se reproduzir mesmo em temperatura de geladeira.

Sabe-se que os Staphylococcus tendem a produzir toxina quando passam por algum tipo de "stress" térmico, ou seja, quando há uma oscilação brusca da temperatura em um tempo relativamente pequeno. Com isso, vale relembrar que, em muitas situações, os leites no Brasil são transportados a temperatura ambiente até as usinas beneficiadoras, quando irão ser refrigerados. Nesse período há a possibilidade da produção da toxina, que não será degradada após o tratamento térmico, e poderá causar intoxicação alimentar no consumidor.

No trabalho de Almeida, Mendes e Silva (2005), a maior freqüência de isolamento em leites provenientes de coleta de latões na plataforma de recepção de indústrias de laticínios da região sul de Minas Gerais, foram os S. aureus $(64,55 \%)$ e que esses microrganismos estavam relacionados às fazendas onde o manejo da ordenha dos rebanhos acontecia de maneira deficiente relacionado ao uso de ordenhadeira mecânica, à não realização do pré e pós dipping e aos rebanhos onde ocorriam falhas no diagnóstico de mastite.

Hoffmann et al. (2004), também pesquisou a presença de Staphylococcus em queijos ralados e demonstrou que das 100 amostras analisadas, $10 \%$ apresentavam-se em desacordo com a legislação federal, ressaltando a importância da qualidade da matéria prima e do processamento dos produtos que se tornam potenciais fontes de toxinfecção alimentar e prejuízos para a indústria e o consumidor. 
No trabalho de Leite, Lima e Reis (2005), das 47 cepas isoladas de Staphylococcus aureus, 85,1\% revelou-se presuntivamente de origem animal, sendo que 0 autor atribui esse resultado à falhas nas condições higiênico-sanitárias.

É importante destacar que a presença de Estafilococos em qualquer quantidade em alimentos é reconhecida como um risco potencial para a saúde publica, uma vez que poderá vir a se multiplicar causando intoxicação alimentar (BARROS et al., 2004).

Já a Klebsiella pneumoniae, pertencente ao gênero dos coliformes e da família Enterobacteriaceae, apresentam variado potencial de patogenicidade para 0 homem, sendo o trato intestinal do homem e de outros animais de sangue quente, 0 habitat natural e principal nicho das enterobactérias. Assim, a presença dessas bactérias no leite indica que o mesmo entrou em contato, de forma direta ou indireta, com material de origem fecal (SILVA; J UNQUEIRA, 1995; NOVAK et al., 2001).

A contaminação de indivíduos, através de alimentos, por Klebsiella spp. pode se tornar um problema de saúde pública, uma vez que é observado na literatura um número cada vez mais freqüente de microrganismos desse gênero resistentes a grande parte dos antibióticos e com envolvimento de infecções hospitalares severas (CASSETARI et al., 2006), infecções urinárias (BLATT; MIRANDA, 2005) e surtos de diarréia aguda (BRASIL, 2007).

Neste trabalho, observou-se que quando se analisa o crescimento bacteriano no leite das cepas de Klebsiella pneumoniae e Staphylococcus spp., encontra-se que, à medida que aumenta a temperatura de armazenamento, passa a haver o predomínio de bactérias gram negativas ( $K$. pneumoniae) nas amostras de leite analisadas, este fato passa a ser preocupante uma vez que indica que o consumidor pode estar ingerindo alimentos com grande quantidade de bactérias causadoras de diarréia ou infecções secundárias, caso o leite não seja procedente de local com higiene e manipulação satisfatórias ou não tenha sido armazenado adequadamente durante as etapas de fabricação.

O trabalho de Barros et al. (2004) demonstra a importância do controle da qualidade da matéria prima (leite) até a elaboração do produto final, uma vez que em seu experimento, encontrou-se 19 amostras de queijo fresco, das 30 amostras analisadas, em desacordo com o limite de até $5 \times 10^{2} / \mathrm{g}$ de coliformes a $45{ }^{\circ} \mathrm{C}$ 
estabelecido pela legislação brasileira (BRASIL, 2001) e 8 amostras das 30 analisadas em desacordo com o máximo permitido pela mesma legislação que é de até $10^{3} / \mathrm{g}$ de Estafilococos coagulase positiva.

No trabalho de Sousa, Toro e Neves (2005) demonstra precariedade dos processos de obtenção e qualidade do leite, uma vez que três das 15 amostras analisadas apresentavam número superior a $5 \times 10^{2} / \mathrm{g}$. a $45^{\circ} \mathrm{C}$. de coliformes.

Avaliando-se os trabalhos acima citados é possível observar que grande parte dos alimentos lácteos podem estar contaminados por Klebsiella spp. Associando estes dados com os resultados obtidos neste trabalho, onde ficou evidenciado que à medida que aumenta a temperatura de armazenamento do leite, passa a haver 0 predomínio de bactérias gram negativas (K. pneumoniae), e sabendo-se que esses microrganismos podem causar uma série de infecções severas e antibiótico resistentes, fica registrado a necessidade de implantar medidas mais efetivas de higiene e controle de qualidade, para evitar a contaminação dos alimentos por esses patógenos e com isso, que pessoas fiquem doentes devido às falhas de produção.

Em relação ao processo de pasteurização, de acordo com a Instituição Normativa $n^{\circ} 51$ (BRASIL, 2002), leite pasteurizado é o leite elaborado a partir do leite cru, refrigerado na propriedade rural, que apresente as especificações de produção, de coleta e de qualidade dessa matéria-prima contidas em Regulamento Técnico próprio e que tenha sido transportado a granel até o estabelecimento processador.

\begin{tabular}{|l|l|l|}
\hline \multicolumn{3}{|c|}{ Antes da Pasteurização } \\
\hline \multicolumn{1}{|c|}{ Produto } & Temperatura (saída) & \multicolumn{1}{c|}{ Temperatura (chegada) } \\
\hline Leite tipo A & Granja leiteira & Granja leiteira \\
\hline Leite tipo B & Maior que $4{ }^{\circ} \mathrm{C}$ por $48 \mathrm{~h}$ & Estabelecimento Industrial adequado maior $7{ }^{\circ} \mathrm{C}$ \\
\hline Leite tipo C & $25{ }^{\circ} \mathrm{C}$ por até $10 \mathrm{~h}$ & $\begin{array}{l}\text { Posto de refrigeração ou Estabelecimento Industrial } \\
\text { adequado }\end{array}$ \\
\hline \multicolumn{3}{|c|}{ Após a Pasteurização } \\
\hline Leite tipo A, B e C: temperatura igual ou inferior a $4^{\circ} \mathrm{C}$ \\
\hline $\begin{array}{l}\text { Temperatura máxima de conservação do leite: } 7{ }^{\circ} \mathrm{C} \text { na propriedade rural ou no tanque } \\
\text { comunitário e } 10{ }^{\circ} \mathrm{C} \text { no estabelecimento processador. }\end{array}$ \\
\hline
\end{tabular}

Fonte adaptada: Instrução Normativa 51, Brasil, 2002.

Quadro 1 - Temperatura de armazenamento do Leite 
No presente estudo avaliou o efeito no processo de pasteurização lenta, quando inserido uma quantidade pré-determinada de microrganismos (Staphylococcus spp., Klebsiella pneumoniae e Staphylococcus spp.,junto à Klebsiella pneumoniae) em leite integral estéril, para observar a curva de morte térmica quando se adiciona cada microrganismo em amostras de leite e quando se adiciona os dois microrganismos na mesma amostra de leite.

De acordo com os resultados obtidos, observou-se que na pasteurização lenta, do leite com a associação de microrganismos (processo similar à realidade dos leites in natura no Brasil), há menos eliminação de UFC quando comparadas, ao mesmo processo, com os microrganismos isolados.

Catão e Ceballos (2001) encontraram leites, com grande quantidade de microrganismo e de diferentes tipos, após a pasteurização, demonstrando que há no mercado, leite com potencial patogênico à população.

Estes resultados são diferentes àqueles obtidos na dissertação de Zappa (2006), onde a autora consegue eliminar todos os microrganismos, utilizando os mesmos métodos de associação entre Cândida spp. e Klebsiella pneumoniae, entretanto, só medindo o número de UFC antes e após a pasteurização lenta.

Já na dissertação de Ruz-Peres (2005), 1,09\% das leveduras e 0,99\% dos fungos filamentos encontrados em amostras de leites crus sobreviveram ao processo de pasteurização lenta, resultado semelhante foi encontrado neste trabalho quando se analisa que $0,03 \%$ das Klebsiella pneumoniae e $3,07 \%$ dos Staphylococcus spp. sobreviveram ao mesmo processo. Entretanto, quando se analisa os microrganismos pasteurizados em associação, observa-se que 36,32\% das Klebsiella pneumoniae e 37,92\% dos Staphylococcus spp. sobreviveram à pasteurização lenta, demonstrando a importância de produzir leite com a menor quantidade de contaminação possível, para que esse seja oferecido ao consumidor alimentos que não coloque em risco sua saúde.

Freo e Reolon (2006), encontraram no respectivo trabalho; no leite in natura índice de coliformes totais e fecais três vezes maior que o permitido pela legislação (1000 NMP/mL). O leite pasteurizado obteve um índice dez vezes maior do que a 
legislação permite (4 NMP/mL). 0 queijo frescal obteve índice três vezes maior que o permitido pela legislação (1000 NMP/mL), concluindo-se que a contaminação dos produtos pode ter sido proveniente da contaminação inicial do leite, falhas no processo de pasteurização ou no envase do produto.

O trabalho de Mendes et al. (2005), avaliou a qualidade microbiológica de leites pasteurizados tipo "C", de três diferentes marcas, comercializadas em Alfenas - MG, sendo que uma das marcas analisadas apresentou um lote com resultados em desacordo com a legislação brasileira, evidenciando que ainda existem irregularidades higiênico-sanitárias durante 0 processamento, envase e/ou armazenamento do leite pasteurizado do tipo " $\mathrm{C}$ ", sendo necessário maior compromisso dos produtos e usinas beneficiadoras com as boas práticas de fabricação, análise de perigos e pontos críticos de controle e maior fiscalização nesses estabelecimentos, fazendo-se cumprir a legislação vigente e oferecendo ao consumidor um produto com qualidade higiênico-sanitária satisfatória e que não implique em riscos para a saúde.

O trabalho Bortolozo et al. (2004) destaca a importância do tempo em relação à quantidade de microrganismos encontrados em produtos lácteos. No referido trabalho, o autor observa que no tempo 0 (zero) de análise todas as amostras (5) de leite (humano) encontravam-se dentro dos padrões biológicos desejáveis, entretanto, quando analisava-se as mesmas amostras armazenadas em geladeira após 12 e $24 \mathrm{~h}$, a população de microrganismos mesófilos aumentou a tal ponto de tornar duas das cinco amostras impróprias para consumo. Neste trabalho, descreve-se a importância de se garantir o menor número possível de microrganismo no produto final para que mesmo após o crescimento natural das bactérias, durante 0 armazenamento, o consumidor adquira o produto de acordo com as legislações vigentes e seguro para a alimentação.

No trabalho de Barbosa, J orge e Ueno (2007), encontrou-se dentre as 175 amostras de leite coletadas na plataforma de uma usina de processamento de Taubaté, $108(61,7 \%)$ amostras contaminadas com Staphylococcus com contagem entre $1,0 \times 10^{2}$ e $2,1 \times 10^{5} \mathrm{UFC} / \mathrm{mL}$ (acima de $1 \times 10^{5} \mathrm{UFC} / \mathrm{mL}$ é considerado perigoso para a produção de enterotoxina). 
Os mesmos autores relatam sobre a importância do processo de pasteurização neste leite devido à alta incidência de microrganismo encontrada, entretanto lembram que o processo de pasteurização apenas diminui a quantidade de cepas viáveis no produto, demonstrando a importância de se trabalhar com alimentos de boa qualidade para que após o processo de pasteurização reste um valor bastante reduzido de cepas viáveis.

Outro ponto importante é lembrar que a cada dia cresce na população, indivíduos com imunidade deficiente, seja pelo aumento do número de pacientes com AIDS, câncer ou outras doenças imunossupressoras, seja pelo crescente nível de estresse em que a população esta exposta, e que leva à diminuição da imunidade deixando a população mais exposta a problemas de ordem alimentar quando ingerirem um alimento de qualidade duvidosa.

Através dos resultados obtidos neste trabalho, observa-se que há grande interação no crescimento bacteriano quando o alimento é submetido a um tempo de armazenamento e esse processo tem relação direta com a temperatura na qual o produto permanece armazenado, demonstrando a importância do cuidado com a higiene durante toda a cadeia produtiva, antes e após o processo de pasteurização, uma vez que esse tipo de tratamento térmico apenas elimina parte das células bacterianas, as quais continuaram a se multiplicar durante 0 tempo de armazenamento até o que alimento seja consumido.

Também fica evidente que quanto melhor a qualidade do leite antes do processo de pasteurização melhor a qualidade do mesmo após o processo de pasteurização. 
CONCLUSÕES 


\section{CONCLUSÕES}

$\mathrm{Na}$ temperatura de $6^{\circ} \mathrm{C}$ não há diferença no crescimento de Staphylococcus spp. e Klebsiella pneumoniae, no leite, e a medida que aumenta a temperatura, até $36^{\circ} \mathrm{C}$, a Klebsiella pneumoniae apresenta crescimento superior ao Staphylococcus spp.

Nas temperaturas de 25 e $36^{\circ} \mathrm{C}$ a Klebsiella pneumoniae associada ao Staphylococcus spp. cresce mais do que quando em cultura pura, o que indica que a contaminação de leite por Klebsiella pneumoniae (contaminação ambiental) irá influenciar mais na qualidade do produto final, comparando-se à contaminação por Staphylococcus spp., oriundo de mastite.

Apesar da curva de morte térmica observada ser mais bem descrita na função cúbica, verificou-se que esta curva é alterada quando há a associação de Klebsiella pneumoniae e Staphylococcus spp., portanto, a interação de microrganismos altera a morte dos mesmos, recomendando-se que novos estudos sejam realizados para que se entenda melhor esse processo. 


\section{REFERÊNCIAS}

ALMEIDA, A. C.; MENDES, C. P. A.; SILVA, D. B. Fatores determinantes da ocorrência de mastite bovina, detectada em rebanhos através da análise de leite em latões. Higiene Alimentar, São Paulo, v. 19, n. 134, p. 81-88, Ago. 2005.

ALTERTHUM, F.; CARVALHAL, L. Controle dos microrganismos. [S.I.:S.n.], 1999. cap. 7, p.75-86.

AMARAL L. A.; ROSSI J UNIOR; O. D.; NADER FILHO; A.; FERREIRA, F. L. A.; BARROS, L. S. S. Ocorrência de Staphylococcus sp. em água utilizada em propriedades leiterias do Estado de São Paulo. Arquivos Brasileiros de Medicina Veterinária e Zootecnia, Belo Horizonte, v. 55, n. 5, p. 620-623, O ut. 2003.

BAR BALHO, T. C. F.; MOTA, R. A. Isolamento de agentes bacterianos envolvidos em mastite subclínica bovina no Estado de Pernambuco. Revista Brasileira de Saúde e Produção Animal, Bahia, v. 2, n. 2, p. 31-36, 2001.

BARBOSA, L.; J ORGE, A. O. C.; UENO, M. Incidência de Staphylococcus coagulase positiva em leite tipo $\mathrm{C}$ e sensibilidade das cepas aos antibióticos. Higiene Alimentar, São Paulo, v. 21, n. 148, p. 105-109, jan/fev. 2007.

BARROS, P. C. O. G.; NOGUEIRA, L. C.; RODRIGUEZ, E. M.; CHIAPPINI, C. C.J . Avaliação da qualidade microbiológica do queijo minas frescal comercializado no município do Rio de J aneiro, RJ . Higiene Alimentar, São Paulo, v. 18, n. 122, p. 5761, J ul. 2004.

BLATT, J . M.; MIRANDA, M. C. Perfil dos microrganismos causadores de infecção do tra to urinário em pacientes internados. Revista panamericana de infectologia. v. 7, n. 4, p. 10-14, 2005.

BEHMER, M. L. A. A. Tecnologia do leite, 15. ed. São Paulo: Ed. Nobel, 1991.

BORTOLOZO, E. A. F. Q.; PIETROSKI, G.; BAGGIO, R.; CÂNDIDO, L. M. B. Padrão microbiológico e sanitário do leite humano, processado em banco de leite. Higiene Alimentar, São Paulo, v. 18, n. 122, p. 85-88, J ul. 2004. 
BRASIL. Agência Nacional de Vigilância Sanitária. Resolução - RDC n 12, de 2 de janeiro de 2001. Regulamento Técnico sobre Padrões Microbiológicos para Alimentos. Disponível em: <http://www.anvisa.gov.br/legis/index.htm> Acesso em: mar. 2007.

BRASIL. Ministério da Agricultura. Instrução Normativa nํ51. Regulamentos Técnicos de Produção, Identidade e Qualidade do Leite tipo A, do Leite tipo B, do Leite tipo C, do Leite Pasteurizado e do Leite Cru Refrigerado e o Regulamento Técnico da Coleta de Leite Cru Refrigerado e seu Transporte a Granel, Diário Oficial da União. Brasília, 20 Set. 2002 , Séc. 1, pg. 13. Disponível em: $<$ http://extranet.agricultura.gov.br/sislegisconsulta/consultarLegislacao.do? operacao=visualizar\&id=8932>. Acesso em: 20 abr. 2007.

BRASIL. Ministério da Agricultura. Regulamento da Inspeção Industrial e Sanitária de Produtos de Origem Animal: aprovado pelo Decreto n 30.691, de 293-52, alterado pelo Decreto n 1255, de 25-6-62. Brasília, D.F .: Ministério da Agricultura, 1980. p. 89. (inspeção Industrial e Sanitária do Leite e Derivados).

Brasil. Ministério da Agricultura. RIISPOA - Regulamento de Inspeção Industrial e Sanitária de Produtos de Origem Animal, artigo 475 (Brasil), Ministério da Agricultura. Departamento Nacional de Inspeção de Produtos de Origem Animal. A provado pelo decreto $n^{0} 30691$ de 29 de março de 1952, alterado pelo Decreto 1255 de 25 de junho de 1962. Alterado pelo Decreto 2244 de 04 de junho de 1997. Brasília-DF .: Ministério da Agricultura, 1997.

BRASIL. Ministério da Agricultura. Secretaria Nacional de Defesa Agropecuária. Laboratório Nacional de Referência Animal - LANARA. Métodos Analíticos para o controle de Produtos de Origem Animal e seus Ingredientes - Métodos FísicoQuímicos. Brasília - DF.: Ministério da Agricultura, 1981.

BRASIL, Ministério da Saúde. Nota técnica. Surto de diarréia aguda em municípios do Estado do Amazonas. Acesso outubro de 2007. Disponível em:

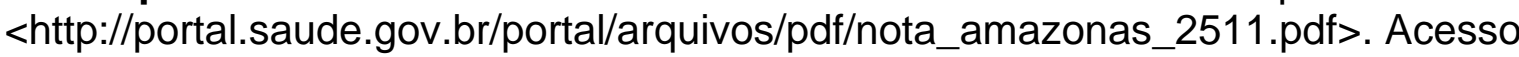
em: 10 Out. 2007.

CASSETTARI, V. C.; SILVEIRA, I. R.; BALSAMO, A. C.; FRANCO, F. S urto em berçário por Klebsiella pneumoniae produtora de beta-lactamase de espectro estendido atribuído à colonização de profissional de saúde portador de onicomicose. Jornal de Pediatria, Rio de J aneiro, v. 82, n. 4, jul-ago, 2006. Disponível em: http://www.scielo.br/scielo.php? script=sci_arttext\&pid=S0021-75572006000500015. Acesso em: 10 Out. 2007. 
CATÃO, R. M. R.; CEBALLOS, B. S. O. Listeria spp, coniformes totais e fecais e $E$. coli no leite crus e pasteurizados de uma indústria de laticínios, no Estado da Paraíba. Ciência e Tecnologia de Alimentos, Campinas, v. 21, n. 3, p. 281-287, Set/Dez. 2001.

EMBRAPA GADO DE LEITE. Importância econômica. J aneiro, 2003. Disponível em:<

http://sistemasdeproducao.cnptia.embrapa.br/FontesHTML/Leite/LeiteCerrado/import ancia.htmL >. Acesso em: 6 Ago. 2005.

FREO, J. D.; REOLON, J . Qualidade dos produtos derivados de carne e leite, industrializados pelas agroindústrias de F rederico Westphalen, RS. Higiene Alimentar, São Paulo, v. 21, n. 140, p. 53-59, Abr. 2006.

HOFFMAN, F. L.; GONÇALVES, T. M. V.; COELHO, A. R.; HIROOKA, E. Y.; HOFFMANN, P. Qualidade microbiológica de queijos ralados de diversas marcas comerciais, obtidos do comércio varejista do município de São J osé do R io Preto, SP. Higiene Alimentar, São Paulo, v. 18, n. 122, p. 62-66, J ul. 2004.

INTER VET. Mastite-Doenças. Disponível em: < Internet:

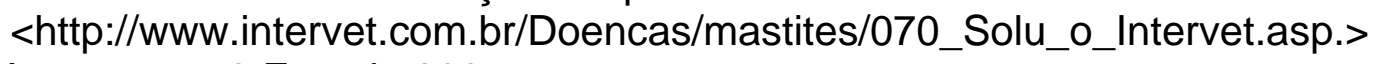
Acesso em: 3 Fev. de 2005.

J ASPER, D. E.; DELLINGER, J . D.; BUSHNELL, R. B. Herd studies on coliform mastitis. Journal American Veterinary Medicine Association, v. 166, n. 8, p. 778780, Abr. 1975.

KIKUCHI, N.; KAGOTA, C.; NOMURA, T.; HIRAMUNE, T.; TAKAHASHI, T.; YANAGAWA, R. Plasmid profiles of Klebsiella pneumoniae isolated from bovine mastitis. Veterinary Microbiology, Amsterdam, v. 47, p. 9-15, 1995.

LEITE, M. M.; LIMA, M. G.; REIS, R. B. O corrência de Staphylococcus aureus em queijo minas tipo frescal. Higiene Alimentar, São Paulo, v. 19, n. 132, p. 89-93, J un. 2004.

MARTINS, L. T.; TRABULSI, L. R.; ALTERTHUM, F.; GOMPERTZ, O. F.; CANDEIAS, J. A. N. Microbiologia. 3. ed. São Paulo, Editora Atheneu, 1999. p. 149-170. 
MENDES, J . B.; TAHAN, F.; OLIVEIRA, F. L. R.; BUENO, J . M.; MONTEIRO, M. R. $P$.; VEIGA, S. M. O. M. Avaliação da qualidade microbiológica do leite pasteurizado tipo "C" comercializado na cidade de Alfenas, MG. Higiene Alimentar, São Paulo, v. 19 , n. 135, p. 64-67, Set. 2005.

MENDONÇA, A. T.; LEAL, D. D. M.; LONDONO, M. M. D.; CARVALHO, E. P. Um microrganismo contaminante de grande importância para o leite e produtos lácteos. Disponível em: < http:www.editora.ufla.br/Boletim/pdfextensao/bol_59.pdf>Acesso em: 3 Fev. 2005.

NONNECKE, J ; NEWBOULD, F. H. S. Biochemical and serologic characterization of Klebsiella strains from bovine mastitis and the environment of dairy cow. American Journal of Veterinary Research. v. 45, n. 11, Nov. 1984.

NOVAK, F. R.; ALMEIDA, J . A. G.; ASENSI, M. D.; MORAES, B. A.; RODRIGUES, $D$. P. R esistência antimicrobiana de coliformes isolados de leite humano ordenhado. Caderno de Saúde Pública. Rio de J aneiro, v.17, n.3 Maio/] un, 2001. Disponível em: <http://www.scielosp.org/scielo.php? script=sci_arttext\&pid=S0102-

311X2001000300026\&lng=en\&nrm=iso\&tlng=en>. Acesso em: 20 Abr. 2007.

REIS, S. R.; SILVA, N.; BRESCIA, M.V. Antibioticoterapia para controle da mastite subclínica de vacas em lactação. Arquivo Brasileiro de Medicina Veterinária e Zootecnia, Belo Horizonte, v. 55, n. 6, Dec. 2003. Disponível em: <http:// www.scielo.br/scielo.php? script=sci_arttext\&pid=S 0102-09352003000600001>. Acesso em: 20 Out. 2005.

RIBEIRO, M. E. R.; PETRINI, L. A.; AITA. M. F.; BALBINOTTI, M.; STUMPF J R. W.; GOMES, J . F.; SCHRAMM, R. C.; MARTINS, P. R.; BARBOSA, R. S. R elação entre mastite clínica, infecciosa e não infecciosa em unidades de produção leiteira na região sul do Rio Grande do Sul. Revista brasileira de agrociências, v. 9, n. 3, p. 287-290, J ul-Set. 2003.

ROBINSON, R, K. (Ed.). Dairy microbiology. Departament of food science, University of Reading, UK. London; New York: E'sevier Applied Science Publishers, 1989. v. 1, 38 p.

RUZ-PERES, M. Avaliação da presença de fungos em amostras de leite cru e estudo da susceptibilidade destes microrganismos às relações temperatural tempo empregadas nos processos de pasteurização e fervura. 2005. $92 \mathrm{f}$. Dissertação (Mestrado em epidemiologia experimental e aplicas às zoonoses) Faculdade de Medicina Veterinária e Zootecnia, Universidade de São Paulo, São Paulo, 2005. 
SALASIA, S. I. O.; KHUSNAN, Z.; LÄMMLER, C.; ZSCHÖCK, M. Comparative studies on pheno- and genotypic propertic of Staphylococcus aureus isolated from bovine subclinical mastitis in central J ava in Indonesia and Hesse in Germany. Jounal of Veterinary Science, v. 5, n. 2, p. 103-109, 2004.

SILVA, N.; J UNQUEIRA, V. C. A. Métodos de análise microbiológica de alimentos. Campinas: ITAL, 1995. p. 228.

SILVA. W. P.; GANDRA, E. A. Estafilococos coagulase positiva: patógenos de importância em alimentos. Higiene alimentar, São Paulo, v. 18, n. 122, p. 32-40, 2004.

SILVA, W. P.; DESTRO, M. T.; LANDGRAF, M.; FRANCO, B. D. G. M. Biochemical characteristic of typical and atypical Staphylococcus aureus in mastitic milk and enviromental sample of brazilian dairy farms. Brazilian Journal of Microbiology. São Paulo, Abr/J un, v. 31, n. 2, 2000.

SOUSA. C. L.; TORO. M. J . U.; NEVES. E. C. A. Avaliação microbiológica e físicoquímica do queijo cottage comercializado na cidade de Belém, PA. Higiene alimentar, São Paulo, v. 19, n. 133, p. 86-91, J ul. 2005.

SOUZA, D. L.; SILVÉRIO, F. L.; OLIVEIRA, T. S.; BIANCHI, M. C.; GOLLUCKE, A. P. B. Ocorrência de Staphylococcus coagulase-positiva em doces recheados vendidos em feiras-livres. Higiene alimentar, São Paulo, v. 19, n. 132, p. 49-57, J un. 2005.

TRABULSI, L. R.; CAMPOS, L. C. Bacteriologia médica In: TRABULSI, L. R.; ALTERTHUM, F.; GOMPERTZ, O. F.; CANDEIAS, J . A. N. Microbiologia. 3. ed. São Paulo, Editora Atheneu, 1999. p. 119-329.

VOLTOLINI, T. V.; SANTOS, G. T.; ZAMBOM, M. A.; RIBAS, N. P.; MÜLLER, E. E.; DAMASCENO, J. C.; ITAVO, L. C. V.; VEIGA, D. R. Influência dos estágios de lactação sobre a contagem de células somáticas do leite de vacas da raça holandesa e identificação de patógenos causadores de mastite no rebanho, Acta Scientiarum, Maringá, v. 23, n. 4, p. 961-966, 2001.

WILSON, D. J .; GONZALEZ, R. N.; DAS, H. H. Bovine mastitis pathogens in New York and Pennsylvania - Prevalência and effects on somatic cell count and milk production. Journal Dairy Science, v. 80, p. 2592-2598, 1997. 
ZAPPA, V. Comparação entre o crescimento no leite de unidades formadoras de colônias de Cândida spp. e Klebsiella pneumoniae, isoladas de tanque de refrigeração de leite, em culturas puras e em associações. $2006.65 \mathrm{f}$. Dissertação (Mestrado em Medicina Veterinária) - Faculdade de Medicina Veterinária e Zootecnia, Universidade de São Paulo, São Paulo, 2006.

ZIA, S.; GIRI, S. N.; CULLOR, J .; EMAU, P.; OSBURN, B. I.; E BUSHNELL, R. B. Role os eicosanoids, histamine, and sertonin in the pathogenesis of Klebsiella pneumoniae-indeced bovine mastitis. American Journal of Veterinary Research, v. 48, n. 11, Nov. 1987.

ZOCCHE, F.; BERSOT, L. S.; BACELLOS, V. C.; PARANHOS, J . K.; ROSA, S. T. M.; RAYMUNDO, N. K. Qualidade microbiológica e físico-química do leite pasteurizado produzido na região do Paraná. Archives of Veterinary Science, Brasil, v. 7, n.2, p. 59-67, 2002 